\title{
Clinical Pharmacokinetics of Triple Immunosuppression Scheme in Kidney Transplant (Tacrolimus, Mycophenolate Mofetil and Corticosteroids)
}

\author{
Robles Piedras Ana Luisa and Monroy Funes Manuel Alejandro \\ Universidad Autónoma del Estado de Hidalgo \\ México
}

\section{Introduction}

Kidney transplantation is now firmly established as the treatment of choice for most patients with End Stage Renal Disease. The short-term outcomes of renal transplantation have dramatically improved over the past several decades; in a large part, this success is due to improvements in immunosuppression and post transplantation medical care. The goal of immunosuppressive strategies in transplantation is to deliver immunosuppression that result in long-term allograft and patient survival, while minimizing the complications of this immunosuppression. Tacrolimus has been one of the cornerstones of immunosuppressive strategies in clinical transplantation. Currently, regimens that are used for induction and maintenance therapy include the concomitant use of Mycophenolate Mofetil and Corticosteroids. The purpose of this chapter is to provide comprehensive and updated information, about the immunosuppressive drugs tacrolimus, mycophenolate mofetil and corticosteroids, which are used as triple immunosuppression scheme to the control of rejection of the transplanted organ.

\section{Tacrolimus}

Tacrolimus was isolated from Streptomyces tsukubaensis in 1984 and is a potent immunosuppressant widely used to prevent acute rejection after solid-organ transplantation, it has a macrolide lactone structure (C44H69NO12, $803.5 \mathrm{~g} / \mathrm{mol}$ ) comprising a 23-member carbon ring and a hemiketal masked b-diketoamide function(Scott et al., 2003). In 1984, the compound tacrolimus was discovered in a soil sample taken from the foot of Mount Tsukuba in Tokyo that was found to possess potent in vitro immunosuppressive qualities. Initially called FR000506, tacrolimus was subsequently found to suppress interleukin-2 production associated with T-cell activation, thus inhibiting the differentiation and proliferation of cytotoxic T cells (Fung, 2004). Tacrolimus has a greater effect on the $\mathrm{T}$ lymphocyte than does an earlier released calcineurin inhibitor, cyclosporine. In a response to antigenic stimulation, in vitro studies on cultured CD4 helper $\mathrm{T}$ 
lymphocytes have demonstrated that tacrolimus is superior to cyclosporine in selectively inhibiting the secretion of various cytokines, including IL-2 and IL-3. This difference may contribute to the greater effect of tacrolimus than cyclosporine on impairing the expression of alloantigen-stimulated $\mathrm{T}$ cells in solid organ transplantation (Vicari-Christensen et al., 2009). The calcineurin inhibitor tacrolimus, has a toxicity profile similar to cyclosporine (Winkler \& Christians, 1995). Two types of side effects must be differentiated: (1) those caused by (over)immunosuppression and (2) those caused by drug toxicity. Immunosupression itself results in an increased incidence of infectious complications and malignancies, mainly lymphoma, as well as failure of vaccination. The principal adverse effects associated with tacrolimus treatment include nephrotoxicity, neurotoxicity, disturbances in glucose metabolism, gastrointestinal (GI) disturbance and hypertension. Susceptibility to infection and malignancy is also increased. Many of the adverse effects of tacrolimus are dose-related; nephrotoxicity, neurotoxicity, glucose metabolism disturbances, GI disturbances and infections may occur more frequently or be more severe at higher whole-blood tacrolimus concentrations. Importantly, these adverse events can often be managed by dosage reductions. Concomitant drugs such as corticosteroids may also contribute to some adverse effects (Naesens, 2009, Plosker, 2000). Because of its variable pharmacokinetics and narrow therapeutic index, monitoring drug concentrations is essential to avoid the risks of over- and under-immunosuppression. For routine clinical practice therapeutic drug monitoring of tacrolimus whole blood concentrations is recommended and target ranges have been defined (Jusko, 1995; Plosker \& Foster, 2000). Increased tacrolimus toxicity is observed with increased tacrolimus concentrations. The large variability in the pharmacokinetics of this drug, makes it difficult to predict what drug concentration will be achieved with a particular dose or dosage change (Staatz \& Tett, 2004; Venkataramanan, 1995). Therapeutic drug monitoring-guided dosing is an important clinical tool to control Tacrolimus exposure and to improve outcome after transplantation. Therapeutic drug monitoring plays an important role in maintaining effective therapeutic levels and avoiding toxic tacrolimus blood concentrations after systemic administration for the treatment of autoimmune diseases (Christians, 2006). Today, tacrolimus has gained worldwide recognition as the cornerstone of immunosuppressant therapy. It is now commercially available in more than 70 countries and has established a significant role in the field of transplantation. According to statistics issued by the Global Observatory on Donation \& Transplantation, an average of 69,300 kidney transplants are performed around the world each year, which constitutes nearly $70 \%$ of solid organ transplants performed world-wide (WHO, 2008). There are currently over 100,000 transplant recipients being treated with immunosuppressive drugs, and tacrolimus is being prescribed to patients with new liver and kidney transplant recipients around the world. Studies have also shown that other adjunctive agents can be safely prescribed in combination with tacrolimus.

\subsection{Mechanism of action}

\subsubsection{Immunosuppressive activity}

Tacrolimus is a macrolide immunosuppressant that acts by a variety of different mechanisms which include inhibition of calcineurin. The drug inhibits T-lymphocyte activation, this may occur through formation of a complex with FK 506-binding proteins (FKBPs). The complex inhibits calcineurin phosphatase. This is believed to inhibit interleukin-2 (IL-2) gene expression in T-helper lymphocytes. Tacrolimus also binds to the 
steroid receptor-associated heat-shock protein 56. This ultimately results in inhibition of transcription of proinflammatory cytokines such as granulocyte-macrophage colonystimulating factor (GM-CSF), interleukin-1 (IL-1), interleukin-3 (IL-3), interleukin-4 (IL-4), interleukin-5 (IL-5), interleukin-6 (IL-6), interleukin-8 (IL-8), and tumor necrosis factor alpha (TNF alpha). The mechanism of action of tacrolimus is largely similar to that of cyclosporin, but tacrolimus is 10 to 100 times more potent. The drugs both inhibit calcineurin but do so via formation of complexes with different immunophilins: Tacrolimus binds to FK-506 binding protein, whereas cyclosporin binds to cyclophilin A. The drugs appear to differ in their effects on patterns of $\mathrm{TH} 2$ cell cytokine expression and possibly some aspects of humoral immunity. Furthermore, lymphocyte sensitivity to the drugs may differ between patients. Calcineurin is a protein phosphatase known as protein phosphatase 2B. It is responsible for activating the transcription of interleukin 2 (IL-2), which stimulates the growth and differentiation of a T-cell response. Calcineurin dephosphorylates a nuclear factor of activated $\mathrm{T}$ cells, and cytoplasmic component transcription factor can then migrate into the nucleus and activate genes involved in IL-2 synthesis. IL-2 is a powerful inflammatory catalyst implicated in allograft rejection. The allograft rejection process begins when an alloantigen is presented to the T-cell receptor and an increase in the cytoplasmic levels of calcium results. This response activates calcineurin by binding regulatory subunits and calmodulin complexes. Calcineurin induces different transcription factors that are important in the IL-2 genes. IL-2 activates helper T lymphocytes and induces the production of other cytokines. In this way, calcineurin governs the process of rejection. The amount of IL-2 produced by the helper T cells is believed to significantly influence the extent of the immune response (Pascual et al., 2002).

\subsubsection{Toxicity}

Because cyclosporine has been used for a much longer time, most data in this field pertain to cyclosporine. The effects of tacrolimus are considered to be similar (Naesens et al., 2009). Tacrolimus resembles cyclosporine in that it can result in nephrotoxicity and the hemolyticuremic syndrome, but it is less likely to cause hyperlipidemia, hypertension, and cosmetic problems and more likely to induce post-transplantation diabetes (Halloran, 2002). Because of its similar mechanism of immunosuppressive activity and its similar clinical toxicity spectrum it is generally assumed that the mechanism involved in tacrolimus toxicity are similar to those for cyclosporine (Christians, 2006). Although the use of cyclosporine and tacrolimus has led to major advances in the field of transplantation, with excellent shortterm outcome, the chronic nephrotoxicity of these drugs is the Achilles' heel of current immunosuppressive regimens. Chronic calcineurin inhibitor nephrotoxicity is associated with mostly irreversible histologic damage to all compartments of the kidneys, including glomeruli, arterioles, and tubulo-interstitium, but the nonspecificity of most lesions makes the differential diagnosis with other injurious processes cumbersome. The pathophysiologic mechanisms underlying CNI nephrotoxicity are partly elucidated, although the main question whether nephrotoxicity is secondary to the actions on the calcineurin-nuclear factor of activated $t$ cells pathway remains largely unanswered. It becomes clear that local renal factors are more important for susceptibility to CNI nephrotoxicity than systemic exposure to cyclosporine and tacrolimus. These factors include variability in P-glycoprotein and CYP3A4/5 expression or activity, older kidney age, salt depletion, the use of Non-Steroidal anti-inflammatory drugs, and genetic polymorphism (Hesselink, 2010; Naesens, 2009). 
Although the exact mechanism is not clear, calcineurin inhibitors are thought to produce nephrotoxicity through their direct action on the kidney. Long-term use of cyclosporine and tacrolimus can also cause hypertension and diabetes, which could contribute to renal failure. Sirolimus, which is not a calcineurin inhibitor but is structurally related to tacrolimus, has also been linked to nephrotoxicity in patients with focal segmental glomerulosclerosis (Bai, 2010). The long term use of cyclosporine produces diminished renal function associated with macrophage infiltration and interstitial fibrosis in the kidney on biopsy. Cyclosporine exposure is also associated with endothelin expression, which is a regulator of inflammation and fibrosis. Hypertension and renal adverse effects are interrelated, so the mechanisms involved in cyclosporine induced hypertension could also influence its adverse effects on the kidney (Bai, 2010). Tacrolimus has been suspected of inducing more BK-related polyomavirus nephropathy than has cyclosporine in patients who have undergone kidney transplantation, especially when used with mycophenolate mofetil, but renal function may be better with tacrolimus (Halloran, 2002; Meier-Kriesche, 2002).

\subsection{Clinical pharmacokinetics}

Tacrolimus is usually administered orally in capsules containing the equivalent of $0.5 \mathrm{mg}, 1$ $\mathrm{mg}$ or $5 \mathrm{mg}$ in a solid dispersion in hydroxipropylmethylcellulose, and an injection solution is available in $5 \mathrm{mg} / \mathrm{mL}$, swell as an ointment for the topical treatment of skin lesions during autoimmune diseases (Astellas, 2009).

\subsubsection{Absorption}

After oral administration absorption of tacrolimus from the gastrointestinal tract after oral administration is incomplete and variable. Generally, bioavailability is about 20 to $25 \%$, but can range from 5\% to $93 \%$. The relatively low fraction of tacrolimus absorbed most likely reflects incomplete absorption, the extent of absorption of this drug from the gastrointestinal tract is also influenced by the activity of P-glycoprotein (P-gp) in enterocytes. P-gp is a transmembrane transporter that is closely associated with CYP3A4 and secretes tacrolimus and its metabolites (Undre, 2003). In most subjects, absorption is rapid with peak blood concentrations occurring within approximately 0.5-2 hours of administration (Astellas, 2009; Venkataramanan, 1995). However, in some individuals, drug uptake occurs more slowly, yielding an essentially flat absorption profile, an extended lag time or secondary peaks. Poor aqueous solubility of tacrolimus and altered gut motility in transplant recipients may be partially responsible. Tacrolimus is absorbed rapidily in most subjects, an oral dose of 0.15 $\mathrm{mg} / \mathrm{kg} / 12$ hours at steady state, the peak concentration (Cmax) averages $45 \mathrm{ng} / \mathrm{mL}$, with a corresponding mean time to peak concentration (Tmax) of 1.5 hours. There is a strong correlation between the area under the concentration-time curve (AUC) and the trough concentration of tacrolimus (Cmin) in whole blood, therefore doses are individualized on the basis of target whole blood trough concentrations (Staatz \& Tett, 2004; Undre, 1999). In stable liver transplant recipients, the oral bioavailability of tacrolimus is decreased if it is taken after food containing moderate fat content (Bekersky et al., 2001a, 2001b). However in a study in a study in renal transplant recipients where tacrolimus trough levels were evaluated prospectively during fasting ingestion of tacrolimus and 1 week after nonfasting ingestion, the results observed were statistically and clinically not significantly different (van-Duijnhoven et al., 2002). Data from a study in 7 patients with type 1 diabetes mellitus and 10 nondiabetic patients, all with end-stage renal failure, also showed that the rate of 
absorption was affected when tacrolimus was taken together with a continental breakfast high in fat content, and food had a greater effect on the absorption of tacrolimus in patients with than without diabetes mellitus (Plosker \& Foster, 2000; van-Duijnhoven, 1998).To avoid the possible effect of food on tacrolimus bioavailability, the drug should be given at a constant time in relation to meals. Oral tacrolimus should not be taken with grapefruit juice since this vehicle inhibits CYP3A4 and/or P-gp contained in the GI tract and markedly increases bioavailability (Christians, 2006).

\subsubsection{Distribution}

In plasma, tacrolimus is highly bound to plasma proteins (99\%) mainly to serum albumin and $\alpha-1$-acid glycoprotein, so the pharmacological activity is considered to be a function of the unbound fraction of tacrolimus. Tacrolimus binds strongly to erythrocytes in the systemic circulation, resulting in a whole blood/plasma concentration distribution range of approximately 4-114 times and whole blood is therefore the medium usually used for assessing therapeutic concentrations (Plosker \& Foster, 2000; Undre, 2003). Erythrocyte concentrations vary in transplant patients, especially those who have received hematopoietic stem cell or kidney transplants. $\alpha$-acid glycoprotein concentrations also vary greatly among patients. Lipophilic drugs such as tacrolimus readily cross membranes and are taken up by adipose tissue. Animal studies indicate that tacrolimus is widely distributed into most tissues, including the lungs, spleen, heart, kidney, pancreas, brain, muscle and liver, tacrolimus crosses the placenta and is detected in breast milk (Staatz \& Tett, 2004; Venkataramanan et al., 1995). At steady state, tacrolimus is distributed extensively in the body and at steady state the majority of the drug resides outside the blood compartment; that is, in the tissues. The plasma volume of distribution is greater than $1,000 \mathrm{~L}$ and in whole blood is approximately $50 \mathrm{~L}$ (Undre, 2003).

\subsubsection{Metabolism and elimination}

Calcineurin inhibitors like tacrolimus and cyclosporine are metabolized by cytochrome P450 (CYP) isoenzyme systems 3A4 and 3A5 in the gut lumen before they even reach the portal vein. P-glycoprotein prevents drug absorption from the gut by promoting efflux into the lumen of the intestine, it has also has a role in systemic clearance of drugs by promoting efflux into the bile for excretion (Tsuchiya et al., 2004). After drugs are absorbed, they are subject to first-pass metabolism and systemic metabolism by CYP3A4 and CYP3A5 in the liver. When CYP3A5 is expressed, it accounts for $50 \%$ of the total hepatic CYP3A content. After administration, tacrolimus, either injected or absorbed into the body, is excreted from the body after receiving extensive metabolism primarily in the liver and to a lesser extent in the intestinal mucosa, by cytochrome P450(CYP)3A4 isoenzymes, with $<0.5 \%$ of the parent drug appearing unchanged in urine and feces (Venkataramanan et al., 1995). The specific number of metabolites formed is unclear, but appears to be at least eight metabolites of tacrolimus have been identified, with two of these exhibiting some activity (Op den Buijsch, 2007; Plosker \& Foster, 2000). Three mono-demethylated metabolites, three di-demethylated metabolites, one mono-hydroxylated metabolite and one metabolite modifed by reactions have been identified. Three metabolites O-demethylated at the 13-, 31- and 15-methoxy group of tacrolimus, respectively, and one monohydroxylated metabolite at the 12-position. The didemethylated metabolites at the 15- and 31,13- and 31-, and 13- and 15-methoxy groups of tacrolimus and one metabolite produced after O-demethylation at the 31-methoxy 
group and formation of a fused 10-membered ring structure through the 19- to 22-carbon of the macrolide ring after oxidation of the 19-methyl group, and of the 36- and 37-vinyl group of tacrolimus (Iwasaki, 2007). Compounds such as tacrolimus that display significant presystemic metabolism and have an intrinsic clearance lower than hepatic blood flow should be sensitive to changes in CYP3A expression. The CYP3A subfamily consists of at least four isoforms: CYP3A4, CYP3A5, CYP3A7 and CYP3A43. As these isoforms have overlapping substrate specificity, it is difficult to segregate their relative contributions to the metabolism of tacrolimus (Staatz \& Tett, 2004). While it is known that CYP3A4 is predominantly localized to the liver and intestines, CYP3A5, on the contrary, is predominantly localized to the kidney (Joy et al., 2007). The isoform CYP3A4 is generally the most abundantly expressed CYP in the adult liver, accounting for $30-40 \%$ of total CYP content, its expression is highly variable, with 10- to 100-fold interindividual differences (Paine et al., 1997). Althoug there is evidence that cytochrome P4503A is mainly responsible for demethylation of tacrolimus, a minor involvement of cytochrome P450 enzymes other than cytochrome P4503A cannot be excluded (Christians, 2006). The reported elimination half-life $\left(\mathrm{t}_{1 / 2}\right)$ of tacrolimus is variable, with mean values of approximately 12 hours in liver transplant recipients, 19 hours in renal transplant recipients and 35 hours in healthy volunteers (Meier-Kriesche, 2002). Less than 1\% of an intravenous dose of tacrolimus is excreted in the urine as unchanged drug, and total urinary elimination (metabolites and unchanged drug) is just over $2 \%$. Faecal elimination accounts for $>90 \%$ of an administered dose, and animal data indicate that the main excretory pathway of tacrolimus metabolites is biliary (Plosker \& Foster 2000; Venkataramanan et al. 1995).

\subsection{Pharmacokinetic variability \\ 2.3.1 Oral bioavailability}

Tacrolimus is highly lipophilic and insoluble in water, these physicochemical properties of tracrolimus cause a large amount of intrasubject variability in tacrolimus oral absorption. Tacrolimus is metabolized in the intestine and liver by the cytochrome P450 (CYP) 3A4 and 3A5 oxidative enzymes. It is also substrate for the P-gp drug transporter, a product of the multidrug resistance (MDR1) gene. Furthermore, CYP3A isoforms and P-gp are under the transcriptional control of the human pregnane $X$ receptor (PXR). Therefore, the interindividual variability of tacrolimus pharmacokinetics might be explained by heterogeneity in CYP3A4, CYP3A5, P-gp or PXR expressions due to genetic polymorphisms (López-Montenegro Soria, et al., 2010). Extrahepatic metabolism by CYP3A4 in the gastrointestinal epithelium is responsible for presystemic elimination of about half of the absorbed dose, whereas first-pass metabolism by CYP3A4 in the liver accounts for an additional $10 \%$ of elimination. The extent of absorption of tacrolimus from the gastrointestinal tract is also influenced by the activity of P-glycoprotein (P-gp) in enterocytes. P-gp is a transmembrane transporter that is closely associated with CYP3A4 and secretes tacrolimus and its metabolites back into the lumen of the gut (Undre et al., 199; Undre, 2003). This extensive presystemic metabolism limits the oral bioavailability of tacrolimus to approximately $25 \%$. The activity of the metabolizing enzyme as well as of the P-gp transporter varies considerably between individuals and between races, and this requires the dosage to be individualized to achieve the desired systemic exposure (Felipe, et al., 2002). Nevertheless, the intra-patient variability in systemic exposure is considered to be low. The low intra-patient variability in the bioavailability of tacrolimus is evidenced by the small number of dose changes required to maintain target whole-blood trough 
concentrations. While the average oral bioavailability of tacrolimus is $25 \%$, there is a large amount of variation in this parameter among patients (4-89\%), small intestine metabolism and/or transport processes contribute greatly (Tuteja et al., 2001). Renal transplant patients may have reduced oral bioavailability for tacrolimus. When given with meals, especially with high fat content food, oral bioavailability of tacrolimus decreases (Venkataramanan et al., 1995). To avoid the possible effect of food on tacrolimus bioavailability, the drug should be given at a constant time in relation to meals. Oral tacrolimus should not be taken with grapefruit juice since this vehicle inhibits CYP3A4 and/or P-glycoprotein contained in the gastrointestinal tract and markedly increases bioavailability. The individual pharmacokinetic response of a renal transplant recipient to immunosuppressive drugs is highly variable. Recent studies have shown that specific genetic variations may alter the pharmacokinetics of these drugs (Rosso Felipe et al., 2009). The metabolic enzyme of tacrolimus is the CYP3A subfamily, including the CYP3A4, CYP3A5, CYP3A7, and CYP3A43 isodynamic enzyme. CYP3A4 and CYP3A5 are the main fractions of these isodynamic enzymes. The mutable site of CYP3A5 is multivariate; the wild type of CYP3A5 is defined as *1, while mutation of 6986 A_G is defined as *3. As disclosed by many studies, the CYP3A5 genotype has a great effect on FK506 concentrations. The amount of CYP3A5 in the liver is large among patients with the * 1 genotype in contrast to the patients with the * 3 genotype, which metabolize tacrolimus faster with lower concentrations in patients with the ${ }^{*} 1$ genotype. Patients with the $* 3 /{ }^{*} 3$ genotype theoretically have high concentration per dosage ratios (Chen et al., 2002; Rosso Felipe et al., 2009; Tuteja et al., 2001). The presence of the CYP3A5*3 genotype is associated with the absence of protein function. López Montenegro et al., demonstrated that Intestinal absorption and metabolism of tacrolimus is significantly affected by the Single Nucleotide Polymorphisms (SNP) in the CYP3A5 and MDR1 genes. Macphee et al., in 2002 in a study with 180 kidney transplant patients, found that a single nucleotide polymorphism in the CYP3AP1 pseudogene $(A / G(44))$ that previously has been noted to be more common in African Americans and strongly associated with hepatic CYP3A5 activity correlated well with the tacrolimus dose requirement, and found a weaker association for a polymorphism in the MDR-1 gene, which influences intestinal P-glycoprotein expression. They conclude that the CYP3AP1 genotype is a major factor in determining the dose requirement for tacrolimus, and genotyping may be of value in planning patient-specific drug dosing. As substrates for CYP3A enzymes and P-glycoprotein, drugs that inhibit or induce these mechanisms may increase or decrease blood tacrolimus concentrations, respectively (Van Gelder, 2002). In clinical studies, CYP3A/P-glycoprotein inhibitors and inducers primarily affect the oral bioavailability of tacrolimus rather than clearance, indicating a key role of intestinal P-glycoprotein and CYP3A. Drugs that interact with P-gp may change the distribution of tacrolimus in tissue and modify its toxicity and immunosuppressive activity (Christians et al., 2002). Ketoconazole, an azole antifungal agent, is known to be a potent inhibitor of P-gp and CYP3A4 and have even been used to reduce the dose of tacrolimus and thus save money. If possible, drugs interfering at the level of the CYP system should be avoided. If tacrolimus and either of these drugs are used concomitantly, close monitoring of tacrolimus concentrations should be performed (Van Gelder, 2002).

\subsubsection{Ethnicity, pharmacogenetic variability}

The importance of interethnic differences in the pharmacokinetics of immunosuppressants has been recognized as having a significant impact on the outcome of transplantation. 
Between-patient variability in drug absorption may be the major cause of inferior transplant outcome observed in special populations such as African-Americans, children and diabetic patients. For example, the poorer transplant outcome observed among African-Americans has been attributed mainly to differences in absorption of cyclosporine, tacrolimus and mycophenolate mofetil (Hariharan et al., 1993; Schweitzer et al., 1998; Stein et al., 2001). Also, compared with white recipients, black transplant patients may also require higher doses of sirolimus to achieve comparable acute rejection rates, even without displaying significant differences in drug absorption. Whether this effect is the result of pharmacodynamic differences comparing black and white patients is not known (Felipe et al., 2002). In a retrospective analysis Fitzimmons et al. found that the oral bioavailability of tacrolimus in African American healthy volunteers and kidney transplant patients was significantly lower than in non-African Americans (Fitzsimmons, 1998). There was no statistically significant difference in clearance. These results were confirmed in a healthy volunteer study. The absolute oral bioavailability of tacrolimus in African American and Latin American subjects was significantly lower than in Caucasians. The results suggested that the observed ethnic differences in tacrolimus pharmacokinetics were, instead, related to differences in intestinal P-glycoprotein-mediated efflux and CYP3A-mediated metabolism rather than differences in hepatic elimination (Mancinelli et al., 2001). Other ethnic groups such as the Japanese populations are not different from the Caucasian population because their transplant outcomes were comparable under usual tacrolimus dosages (Ochiai et al., 1995). Drugs metabolized by CYP3A4/5 inhibited tacrolimus metabolism, with ketoconazole being the most potent. Ketoconazole, cyclosporine A, diltiazem, erythromycin, and fluconazole were reported as the drugs that elicit clinically relevant drug interactions with tacrolimus (Christians et al., 2002). These results indicate the potential for metabolic interactions between tacrolimus and co-medicated drugs metabolized by CYP3A4/5. Rifampicin decreased the blood levels of tacrolimus in kidney and liver transplant patients. Rifampicin treatment caused a decrease of tacrolimus blood levels in healthy volunteers when compared to pretreatment levels (Hariharan et al., 1993; Stein et al., 2001). Coadministration of rifampicin significantly increased tacrolimus clearance and decreased tacrolimus bioavailavility. A combination of fluconazole and tacrolimus augments tacrolimus blood levels (Mañez et al., 2002). In kidney transplantation, it was also reported that in a combination of fluconazole at $100 \mathrm{mg}$ to tacrolimus, the dosage of tacrolimus could be reduced by forty percent without changing tacrolimus trough levels (Toda et al., 2002). CYP3A proteins are involved in the metabolism of more than $50 \%$ of the drugs in use, including tacrolimus. Pharmacogenomic studies have shown that SNP in intron 3 of the CYP3A5 gene correlate with different expression levels, because of the appearance of a cryptic-splice site resulting in either the presence $\left({ }^{*} 1 /{ }^{*} 1\right.$ and SNP $\left.* 1 /{ }^{*} 3\right)$ or absence (SNP ${ }^{*} 3 /{ }^{* 3}$ ) of the protein (Yu et al., 206; Barrera-Pulido et al.,2008). Interindividual CYP3A expression in the liver varies 10 - to 100 -fold and up to 30 -fold in the small intestine, but there is no significant polymorphism of CYP3A4. Only people with at least one CYP3A45*1 allele express significant amounts of CYP3A45*3and CYP3A45*6 cause alternative splicing and protein truncation that results in the absence of CYP3A5 enzyme (Macphee et al., 2002). Greater than $60 \%$ of African Americans compared with less than $10 \%$ of the Caucasian population possess the CYP3AP1 $\mathrm{G}_{-44}$ allele, which is necessary for CYP3A5 expression. In humans expressing CYP3A5, it represents at least $50 \%$ of the total hepatic content of CYP3A. Together with CYP3A4 it is the most abundant CYP enzyme in the small intestine. CYP3A5 is probably the most important genetic contributor to interindividual and interracial 
differences in CYP3A-dependent drug clearance. As discussed above, another important factor affecting the pharmacokinetics of tacrolimus is the expression of MDR1, the gene encoding the active transporter P-glycoprotein. Homozygous individuals for the T-allele for MDR1, C3435T, have significantly lower intestinal and leukocyte P-glycoprotein expression than C homocygotes ((Macphee et al., 2002; Schaeffeler et al., 2001). MDR1 C3435T is significantly more prevalent in the Caucasian than in the African American population. MacPhee (2002) demonstrated that the dose-normalized tacrolimus blood concentration after renal transplantation was associated with a SNP in the CYP3AP1 gene, probably through linkage with an SNP in the CYP3A5 gene. Individuals with at least one CYP3A5*1 allele synthesize CYP3A5 and CYP3A5*3/*3 homozygotes do not (Paine et al., 1997). In another study MacPhee et al. (2005) showed results with direct typing of the CYP3A5 genotype for a group of 180 kidney-only transplant recipients. South Asian and white patients with at least one CYP3A5*1 allele achieved twofold lower dose-normalized tacrolimus blood concentrations compared with CYP3A5*3/*3 homozygotes, confirming their previous findings for the CYP3AP1 SNP. There was a significant delay in achieving target blood concentrations in those with at least one CYP3A5*1 allele. They conclude that the Determination of the CYP3A5*1/*3 genotype could be used to predict the tacrolimus dose requirement and, given incomplete linkage, would be better than determination of the CYP3AP1 genotype. For renal transplant recipients receiving tacrolimus as an immunosuppressant, practitioners can expect CYP3A5*1 carriers to have a tacrolimus clearance $25-45 \%$ greater than that of $C Y P 3 A 5 * 3$ homozygotes, with proportional dosing needs to maintain adequate immunosuppression. Since inadequate immunosuppression is linked to graft rejection, evaluation of CYP3A5 polymorphisms may be helpful in determining an appropriate starting dosage, rapidly achieving adequate immunosuppression, and ultimately improving the outcome of renal transplantation (Utecht et al., 2002).

\subsubsection{Sex}

Gender-related differences in pharmacokinetics have frequently been considered as potentially important determinants for the clinical effectiveness of drug therapy. The human multidrug-resistance gene 1 (MDR1) gene product P-gp has been identified as a major determinant in the pharmacokinetics of numerous drugs. Additional other drug transporters are also assumed to play a major role in absorption, distribution and/or renal and hepatic excretion of therapeutic agents. Gender differences have been noted in the hepatic expression of MDR1, with women displaying only one-third to one-half of the hepatic P-gp level of men. Low P-glycoprotein activity in the liver is suggested to result in increased hepatic CYP3A metabolism for cosubstrates of CYP3A and P-glycoprotein. Low Pgp activity in the gut wall results in shorter gut wall transit time and, hence, decreased gut wall CYP3A metabolism (Lown et al., 1997; Meibohmet al., 2002). The most important pharmacokinetic parameter influenced by sex differences seems to be oral biovailability (Christians, 2006; Harris et al., 2002). Although no difference in dosing by sex was found in the tacrolimus kidney transplant trials and dosing recommendations for male and female patients are the same, sex differences were found when tacrolimus and ketoconazole were coadministered (Fitzsimmons et al., 1998; Tuteja et al., 2001). Female-specific issues such as pregnancy, menopause, oral contraceptive use and menstruation may also have profound effects on drug metabolism. These effects can often be clinically important (Harris et al., 2001). 


\subsubsection{Age}

As already mentioned, tacrolimus is primarily metabolized by cytochrome P450(CYP)3A enzymes in the gut wall and liver. It is also a substrate for P-gp, which counter-transports diffused tacrolimus out of intestinal cells and back into the gut lumen. Age-associated alterations in CYP3A and P-gp expression and/or activity, along with liver mass and body composition changes, would be expected to affect the pharmacokinetics of tacrolimus in the elderly (Staatz \& Tett, 2002). Several changes in hepatic function and structure have been noted in the elderly; among them, two of the most important are an absolute (and relative to bodyweight) decrease in the size of the liver, and reduced regional blood flow to this organ (Hämmerlein et al., 2002). It is likely that inter- and intraindividual pharmacokinetic variability associated with tacrolimus increase in elderly populations. In addition to pharmacokinetic differences, donor organ viability, multiple co-morbidity, polypharmacy and immunological changes need to be considered when using tacrolimus in the elderly. Aging is associated with decreased immune responsiveness, a slower body repair process and increased drug adverse effects. Elderly liver and kidney transplant recipients are more likely to develop new-onset diabetes mellitus than younger patients, elderly transplant recipients exhibit higher mortality from infectious and cardiovascular causes than younger patients, but may be less likely to develop acute rejection, also have a higher potential for chronic allograft nephropathy and a single rejection episode can be more devastating (Staatz \& Tett, 2002). Pharmacokinetic parameters observed in adults may not be applicable to children, especially to the younger age groups. In general, patients younger than 5 years of age show higher clearance rates regardless of the organ transplanted or the immunosuppressive drug used (del Mar Fernández De Gatta et al., 2002). Only limited information is available on the pharmacokinetics of tacrolimus in pediatric patients, the rate and extent of tacrolimus absorption after oral administration do not seem to be altered in pediatric patients. The volume of distribution of tacrolimus based on blood concentrations in pediatric patients $(2.6 \mathrm{~L} / \mathrm{kg})$ is approximately twice the adult value. Blood clearance of tacrolimus is also approximately twice as high in pediatric $(0.14 \mathrm{~L} / \mathrm{h} / \mathrm{kg})$ compared with adult $(0.06 \mathrm{~L} / \mathrm{h} / \mathrm{kg})$ patients. Consequently, $\mathrm{t}_{1 / 2} \beta$ does not appear modified in children, but oral doses need to be generally 2-fold higher than corresponding adult doses to reach similar tacrolimus blood concentrations. More pharmacokinetic studies in pediatric patients are, however, needed to rationalize the use of therapeutic drug monitoring for optimization of tacrolimus therapy in this patient population (Wallemacq \& Verbeeck 2001).

\subsection{Time after initiation of treatment}

It is well established that tacrolimus pharmacokinetics changes with the time after transplantation are the results of a reduced clearance or an increase in oral bioavailability (Staatz \& Tett, 2004). Possible reasons include stabilization of the patient with reduction of postsurgical stress, hematocrit, ischemia-reperfusion injury and stabilization of transplant organ function, especially if the latter directly affects tacrolimus pharmacokinetics such as the liver. Also, immunosuppressive drugs affect expression and activity of CYP3A enzymes and P-gp (Christians et al., 2002). There is evidence that induction of CYP3A and P-gp by corticosteroids is responsible for the requirement to reduce tacrolimus doses as corticosteroid doses are tapered (Hesselink et al., 2003; Plosker \& Foster 2000; Undre 1998). After cessation of concomitant steroid treatment, tacrolimus exposure increase by $25 \%$ (del Mar Fernández De Gattaet al., 2002). 


\subsection{Drug-Drug interactions}

Drug interactions occur when the efficacy or toxicity of a medication is changed by coadministration of another drug (Dresser et al., 2000). The clinical relevance of pharmacokinetic drug interactions depends on a number of considerations, of which the therapeutic index of the drug is the most important. Potential sites of pharmacokinetic drug interactions include the gastrointestinal tract, protein- and tissue-binding sites, drug metabolising enzymes, drug transporter systems, biliary excretion and enterohepatic recirculation as well renal excretion (Van Gelder, 2002). There are several factors involved in absorption of a drug after oral administration, all of which can be the target of drug interactions: delivery to the intestine ( $\mathrm{pH}$, gastric emptying and food), absorption from the intestinal lumen (dissolution, lipophilicity, stability, active uptake), intestinal metabolism (phase I or II metabolism), active intestinal drug efflux pumps, and subsequent hepatic first pass extraction (Christians et al., 2002). Drug interactions with tacrolimus fall into two basic categories. The first are agents known to cause nephrotoxicity when administered by themselves, the second category of drug interactions involves inhibition or induction of tacrolimus metabolism. Because tacrolimus is metabolized extensively by CYP3A4 isoenzymes and P-glycoprotein, drugs that are either inhibitors or inducers of this system may increase or decrease serum concentrations of tacrolimus. CYP3A4 inhibitors that increase whole blood concentrations of tacrolimus include antifungal agents (fluconazole, voriconazole, ketoconazole, itraconazole, and clotrimazole), calcium channel blockers (diltiazem, nifedipine, nicardipine, and verapamil), macrolide antibiotics (erythromycin, clarithromycin, and troleandomycin), prokinetic drugs (metoclopramide and cisapride), protease inhibitors (indinavir, saquinavir, ritonavir, nelfinavir, amprenavir, and atazanavir), and grapefruit juice. CYP3A4 inducers that are known to decrease tacrolimus concentrations include anticonvulsants (carbamazepine, phenytoin, and phenobarbital); rifamycins (rifampin and rifabutin), and St John's wort (Vicari-Christensen et al., 2009). Potential pharmacokinetic interactions between tacrolimus and mycophenolate mofetil has been evaluated since these drugs are frequently used in combination (Zucker et al., 2002; Undre at al., 2002; Hübner et al., 1999). Results indicate that mycophenolate mofetil does not significantly affect the pharmacokinetics of tacrolimus in renal and hepatic transplant recipients. However, tacrolimus may have an effect on the pharmacokinetics of mycophenolic acid, the active metabolite of mycophenolate mofetil. In renal transplant recipients who were converted from cyclosporin to tacrolimus therapy (while being maintained on the same dosage of mycophenolate mofetil), plasma trough concentrations of mycophenolic acid were significantly increased (approximately doubled) as were AUC values for mycophenolic acid (increased by about one-third) after conversion from cyclosporin to tacrolimus (although there was no mycophenolate mofetil control group in the study) (Plosker \& Foster, 2000). Because of the large number of potentially interacting agents, and the critical nature of the drugs involved in the treatment of transplant patients, complete avoidance of drug interactions with tacrolimus is not possible. Thus, most drug interactions with tacrolimus are managed using appropriate tacrolimus dosage modification with tacrolimus concentration monitoring as a guide.

\subsection{Adverse reactions}

The calcineurin inhibitors tacrolimusa and cyclosporine, are the mainstay of immunosuppressive therapy in solid organ transplantation. These drugs produce severe 
adverse effects and tended to occur most frequently in the first few months after transplant and decline thereafter, possibly in ther line with reduction in dosages of the immunosuppressants (Bai et al., 2010). There are several principal adverse effects associated with tacrolimus. Nephrotoxic effects can occur in up to $52 \%$ of patients and limit the use of the drug. However, nephrotoxic effects may be difficult to distinguish from other causes of renal failure in kidney transplant recipients. Neurotoxic effects may be manifested by tremors (15\%-56\%), headache (37\%-64\%), insomnia (32\%-64\%), and paresthesias $(17 \%-40 \%)$. Post-transplant diabetes mellitus is one of the more serious metabolic disorders associated with calcineurin inhibitors treatment (Scott et al., 2003). Cyclosporine appears to be less diabetogenic than tacrolimus, but both agents may impact directly the transcriptional regulation of insulin gene expression in the pancreatic $\beta$ cells. Based on an analysis of 3365 kidney recipients, the primary risk factors identified for posttransplantation diabetes included older age, female, increased Body Mass Index, and tacrolimus-based therapy.[24] Other studies have also identified tacrolimus as a risk factor for posttransplantation diabetes in addition to older age (> 40 years), Body Mass Index greater than $25 \mathrm{~kg} / \mathrm{m}^{2}$, positive hepatitis $C$ serology, family history of diabetes, metabolic syndrome, African-American or Hispanic race-ethnicity, and higher mean pretransplantation plasma glucose concentration. The risk factors for posttransplantation diabetes are similar to those for type 2 diabetes (Markell, 2004; González-Posada at al., 2004; Kamar et al., 2007). Hypertension (38-89\%) is common, as is drug-induced diabetes $(24 \%)$, exacerbated by the use of corticosteroids. Gastrointestinal disturbances reported are diarrhea (37\%-72\%), nausea (32-46\%), constipation (23-35\%), and anorexia (34\%). Malignant neoplasms such as lymphoma and lymphoproliferative disease occur rarely $(1.5 \%)$. Finally, the risk of bacterial, viral and fungal infections is increased (up to $45 \%$ ), because of the immunosuppressive effect of tacrolimus..

\subsection{Therapeutic drug mpnitoring}

Therapeutic drug monitoring has been used as an essential tool to individualize immunosuppressive drug therapy in vascularized organ transplant recipients, allowing a more rational use of drugs with narrow therapeutic index such as cyclosporine, tacrolimus, sirolimus, and mycophenolate acid (Rosso Felipe et al., 2009). Tacrolimus whole-blood through concentrations have been found to correlate well with the area under the concentration-time curve measurements in liver, kidney and bone marrow transplant recipients $(\mathrm{r}=0.91-0.99)$. Thus, through concentrations are a good index of overall drug exposure, and are currently used for routine monitoring as part of patient care posttransplantation (Jusko, 1995; Staatz et al., 2001). This approach offers the opportunity to reduce the pharmacokinetic variability by implementing drug dose adjustments based on plasma/blood concentrations. Drug levels are obtained as predose (12 hours after previous dose) trough concentrations in whole blood (Cattaneo et al., 2009). These trough levels correlate reasonably well with area under the curve, with total area under the curve being an accurate measure of drug exposure (Kapturczak et al., 2004). Therapeutic ranges of tacrolimus after kidney transplantation are reported as a range for various times after transplant: 0-1 month, 15-20 $\mu \mathrm{g} / \mathrm{L}$; 1-3 months, 10-15 $\mu \mathrm{g} / \mathrm{L}$; and more than 3 months, 5-12 $\mu \mathrm{g} / \mathrm{L}$ (Scott et al., 2003). Pharmacokinetic therapeutic drug monitoring can only be of clinical relevance when the pharmacodynamics response is correlated to drug exposure. In a retrospective analysis based on adult renal transplant recipients during the first month after transplantation, tacrolimus through blood concentrations measured, were correlated with 
rejection episodes. The median through blood concentration in patients with rejections $(5.6 \pm 1.6 \mathrm{ng} / \mathrm{mL})$ were significantly lower than in patients without rejection $(9.2 \pm 3.5 \mathrm{ng} / \mathrm{mL})$. A rejection rate of $55 \%$ was found for patients with median tacrolimus through blood concentrations between 0 and $10 \mathrm{ng} / \mathrm{mL}$, whereas no rejection was observed in patients with median tacrolimus through blood concentrations between 10 and $15 \mathrm{ng} / \mathrm{mL}$ (Staatz at al., 2001). Tacrolimus blood concentrations are monitored 3 to 7 days a week for the first 2 weeks, at least three times for the following 2 weeks, and whenever the patient comes for an outpatient visit thereafter (Jusko \& Kobayashi, 1993). On the basis of the terminal half-life of tacrolimus, it was suggested to start monitoring tacrolimus blood concentrations 2 to 3 days after initiation of tacrolimus treatment after the drug has reached steady state. However it is important to reach effective drug concentrations early after transplantation to decrease the risk of acute rejection and to avoid excessive early calcineurin inhibitors concentrations that may be severely damaging after reperfusion of the transplanted organ (Shaw et al., 2002). The frequency of therapeutic drug monitoring of tacrolimus should be increased in the case of suspected adverse events or rejection, when liver function is deteriorating, after dose adjustments of the immunosuppressants, change of route of administration, or change of drug formulations, when drugs that are known to interact with CYP3A or P-gP are added or discontinued, or when their doses are changed, in case of severe illness that may affect drug absorption or elimination such as severe immune reactions and sepsis, or if noncompliance is suspected (Christians at al., 2006). Recent advances in molecular biology and genetic information made available through the Human Genome Project has had a great influence in the biomedical and pharmaceutical area. It is well established that large numbers of patients demonstrate great differences in drug bioavailability. Nowadays the advent of the genomic era has brought several new fields of study, including pharmacogenomics, which seek to link drug treatment with the individual's genetic makeup. Pharmacogenomics holds many promises for improved treatment of a large variety of medical conditions, including immunosuppression for organ transplantation (Cattaneo et al., 2004; Danesi et al., 2000). In recent years, extensive studies on pharmacogenetics of immunosuppressive drugs have been focused on the contribution of drug metabolizing enzyme cytochrome P450 (CYP) 3A (CYP3A4 and CYP3A5) and the drug transporter P-gp to the individual administration of cyclosporine and tacrolimus, for they are thought to be the main determinant of the pharmacokinetics of currently used immunosuppressive drugs (Macphee et al., 2002). Those involved in therapeutic drug monitoring are now realizing the potential role of pharmacogenomics in influencing individual patient's exposure to immunosuppressive agents and concomitant therapy. As rapid techniques for assessing genetic polymorphisms become available, they are likely to play a significant part in planning the initial doses of immunosuppressive drugs and tailor maintenance therapy (Cattaneo et al., 2004).

\section{Mycophenolate}

The search for inhibitors of the novo purine synthesis led to the ancient compound mycophenolic acid discovered in 1896. MPA was known to be immunosupresive, to inhibit lymphocyte DNA synthesis, and to inhibit guanine nucleotide synthesis in tumor cells. It was found to block the novo purine biosynthesis by inhibit the key enzyme in this pathway, inosine monophosphate dehydrogenase (IMDPH). The principle of the Mycophenolate mofetil arose from de observation that defects in the novo purine biosynthesis create immunodeficiency without affecting other tissues. Mycophenolate mofetil (MPM) is the 2- 
morpholinoethyl ester of mycophenolic acid (MPA), an immunosuppressive agent IMPDH inhibitor. The chemical name for MMF is 2-morpholinoethyl (E)-6-(1,3-25 dihydro-4hydroxy-6-methoxy-7-methyl-3-oxo-5-isobenzofuranyl)-4-methyl-4-6 hexenoate. It has an empirical formula of $\mathrm{C}_{23} \mathrm{H}_{31} \mathrm{NO}_{7}$, a molecular weight of 433.50 (Christians et al., 2006), is a potent, selective, noncompetitive, reversible inhibitor of IMPDH, an essential enzyme in de novo synthesis of purines (i.e. guanosine), MPA has potent cytostatic effects on lymphocytes. Inhibits proliferative responses of $\mathrm{T}$ and $\mathrm{B}$-cells to both mitogenic and allospecific stimulation and suppresses antibody formation by B-cells. By preventing glycosylation of lymphocyte and monocyte glycoproteins involved in intracellular adhesion to endothelial cells, MPA may inhibit recruitment of leukocytes to sites of inflammation and graft rejection (Pillans et al., 2001; Kiberd, et al., 2004; van Gelder et al., 1999).

\subsection{Mechanism of action}

The salvage pathway of purine synthesis in lymphocytes is less active than the de novo synthesis of purines. Inosine monophosphate is converted to guanosine monophosphate by inosine monophosphate dehydrogenase. During T-cell activation, the activity of both types I and II inosine monophosphate dehydrogenase enzymes increases by tenfold. Mycophenolate mofetil is converted in the liver by ester hydrolysis to mycophenolic acid, which in turn non-competitively and reversibly inhibits types I and II inosine monophosphate dehydrogenase activity during DNA synthesis in the $S$ phase of the cell cycle. In the salvage pathway, guanine is converted to guanine monophosphate by the enzyme hypoxanthine-guanine phosphoribosyltransferase. MPM is commonly used in transplanted patients; it is a non-competitive reversible inhibitor of $5^{\prime}$-mono phosphate inosine dehydrogenase, which controls the synthesis of guanosine triphosphate; its mechanism of action is by depletion of intracellular levels of guanosine triphosphate (GTP) and deoxyguanosine triphosphate (dGTP), which leads to suppression of DNA synthesis in $\mathrm{T}$ and $\mathrm{B}$ lymphocytes stimulated with antigens or mitogens. It does not inhibit early events of lymphocytes activation including cytokine production. It also inhibits antibody formation and production of adhesion molecules on the cellular surface. It has been used to prolong transplant survival in animal and human models in 5/6 nephrectomy to reduce cellular infiltration within the tubule and interstitium with decreased renal damage been observed in the remnant kidney (Bullingham, 1996a, 1996b).

\subsection{Clinical pharmacokinetics}

\subsubsection{Onset \& plasma concentrations}

Peak mycophenolic acid levels occur approximately one hour post dose, with a secondary peak occurring 6 to 8 hours later, due to enterohepatic recirculation of MPA glucuronide (MPAG) and its hydrolysis back to mycophenolic acid in the gastrointestinal tract. The apparent elimination half-life of mycophenolic acid after a single oral dose of MMF is approximately 18 hours. The AUC is found to increase following renal transplantation, stabilising after about a month of therapy. Food reduces the Cmax but has no effect on the AUC. Single dose studies in chronic renal impairment (creatinine clearance < $25 \mathrm{~mL} / \mathrm{min} / 1.73 \mathrm{~m}^{2}$ ) showed that the AUC for mycophenolic acid was $28-75 \%$ higher than in individuals with no or milder renal impairment (Christians et al., 2006). A secondary plasma MPA peak is often seen 6 to $12 \mathrm{~h}$ after oral administration of MMF, suggesting enterohepatic circulation of the drug. Because of this secondary rise in plasma MPA 
concentration, the apparent mean terminal half-life of MPA is $17.9 \mathrm{~h}$ in healthy subjects. MPA is converted in the liver to the pharmacologically inactive MPAG, which is excreted by the kidney. Plasma MPA is extensively bound to albumin, and a mean protein binding of 97\% has been reported in normal plasma (Bullingham, 1996a, 1996b). Renal transplant patients who received oral mycophenolate mofetil $1.5 \mathrm{~g}$ twice daily achieved maximal plasma concentrations of $13.5 \mu \mathrm{g} / \mathrm{mL}$ early postransplant (less than 40 days) and 24.1 $\mu \mathrm{g} / \mathrm{mL}$ late posttransplant (at least 3 months). The maximum plasma concentrations were achieved at 1.21 hours and 0.9 hours, respectively. Following kidney transplantation, 10 patients who received oral mycophenolate mofetil $1 \mathrm{~g}$ twice daily achieved mean maximum plasma concentrations of mycophenolic acid of $11.1 \mu \mathrm{g} / \mathrm{mL}, 11.9 \mu \mathrm{g} / \mathrm{mL}$, and $14.9 \mu \mathrm{g} / \mathrm{mL}$ on days 2, 5, and 28, respectively. The maximum concentration was achieved at 2.18 hours, 1.9 hours, and 1.63 hours (Johnson et al., 1999). Renal transplant patients $(n=12)$ who received oral mycophenolic acid $720 \mathrm{mg}$ twice daily achieved maximal plasma concentrations of $15 \mu \mathrm{g} / \mathrm{mL}, 26.2 \mu \mathrm{g} / \mathrm{mL}$, and $24.1 \mu \mathrm{g} / \mathrm{mL}$ at 2 weeks, 3 months, and 6 months posttransplant, respectively. The maximum plasma concentrations were achieved at 1.8 hours, 2 hours, and 2 hours (Sollinger et al., 1992).

\subsubsection{Absorption}

MPM is well absorbed orally with a mean bioavailability of $94 \%$. After oral administration, it is rapidly and essentially completely absorbed, and then essentially completely converted to MPA, the active immunosuppressant species. In renal transplant recipients, very low serum levels of mycophenolic acid were achieved after oral mycophenolate mofetil therapy in the early posttransplantation period; serum levels increased significantly after 20 days of treatment, suggesting potentially impaired absorption or altered metabolism of the ester in uremic patients. Following oral and IV administration, MPM undergoes rapid and complete metabolism to MPA, the active metabolite; however, Mycophenolate sodium (MPA $720 \mathrm{mg}$ ) and MPM $1 \mathrm{~g}$ result in bioequivalent MPA exposure. Food decreases peak plasma concentrations of MPA by 33-40\%; no effect on the MPA AUC (Bullingham, et al., 1998).

\subsubsection{Distribution}

MPA plasma protein binding is $\geq 97-98 \%$, mainly in albumin. Severe renal impairment has been shown to decrease the binding of mycophenolic acid to albumin, thereby elevating the concentration of mycophenolic acid free fraction in serum. In addition, increased levels of the mycophenolic acid glucuronide metabolite in these patients may compete with free mycophenolic acid for binding with albumin. In patients with renal impairment or delayed graft function, protein binding may be decreased (Meier-Kriesche et al., 2000). MPM hydrochloride protein binding is $97 \%$, in albumin principally. MPA half-life is about $8-17.9$ hours. MPM volume of distribution is approximately $4 \mathrm{~L} / \mathrm{Kg}$. The mean volume of distribution for mycophenolic acid was $54 \mathrm{~L}$ at steady state and $112 \mathrm{~L}$ at elimination phase (Bullingham, et al., 1998).

\subsubsection{Metabolism and excretion route}

MPM undergoes complete metabolism to MPA; metabolism occurs presystemically following oral administration. MPA is metabolized by glucuronyl transferase to the phenolic glucuronide of MPA. The phenolic glucuronide is converted to MPA via enterohepatic recirculation. MPM is rapidly hydrolysed extensively in the liver to MPA; this metabolite is 
conjugated to form the pharmacologically inactive mycophenolic acid glucuronide. Approximately $87 \%$ of the oral dose is excreted as MPAG in the urine. MPM is excreted in urine $(93 \%)$ as the phenolic glucuronide of MPA $(87 \%)$ and in feces $(6 \%)$. MPS is excreted principally in urine as phenolic glucuronide of MPA (> 60\%) and as unchanged MPA (3\%). The mean renal clearance of MPA glucuronide was $15.5 \mathrm{~mL} / \mathrm{min}$ following the administration of delayed release mycophenolic acid to stable renal transplant patients (Christians et al., 2006). Deconjugation of the glucuronide to mycophenolic acid may occur in humans via the action of intestinal or intestinal microflora beta-glucuronidase, with subsequent reabsorption of mycophenolic acid (Mourad et al., 2002; Platzet al., 2002). In vivo, mycophenolic acid glucuronide is converted to mycophenolic acid via enterohepatic recirculation. MPM total body clearance is 140 to $193 \mathrm{~mL} / \mathrm{min}$. The plasma clearance of MPA is $193 \mathrm{~mL} / \mathrm{min}$ following oral administration of mycophenolate mofetil. The mean clearance of mycophenolic acid was $140 \mathrm{~mL} / \mathrm{min}$ following oral administration of the delayed release mycophenolic acid tablet to stable renal transplant patients. The plasma clearance of MPA is $177(+/-31) \mathrm{mL} / \mathrm{min}$ following IV administration of MPM (Bullingham, et al., 1998; Meier-Kriesche et al., 2000).

\subsection{Pharmacokinetic variability}

The pharmacokinetics of MMF is complex; some patients achieve a peak in 1 to $2 \mathrm{~h}$ and a second peak at 5 to $6 \mathrm{~h}$ due to enterohepatic circulation. In some patients, the second peak (Cmax) is as much as $50 \%$ of the total peak concentration. A maximum concentration of $>10$ $\mu \mathrm{g} / \mathrm{mL}$ is associated with side effects. There is little correlation with area under the concentration curve (AUC) and dose. The AUC in the first $12 \mathrm{~h}$ does correlate with propensity to reject if it is $<30 \mu \mathrm{g} . \mathrm{h} / \mathrm{mL}$ or toxicity if it is $>60 \mu \mathrm{g} . \mathrm{h} / \mathrm{mL}$. The desired exposure is 35 to $60 \mu \mathrm{g} . \mathrm{h} / \mathrm{mL}$ (Shaw et al., 2000). Mycophenolic acid AUC is increased by renal dysfunction, which may be clinically relevant early after transplantation or during rejection episodes. Plasma concentrations of MPA glucuronide higher in nontransplant subjects with severe renal impairment than in those with mild impairment or normal renal function. At the same time, plasma concentrations of MPA glucuronide higher in transplant patient with delayed renal graft function than in patients not experiencing delayed graft function. Dialysis does not remove MPA. Plasma concentrations of free (unbound) MPA and total MPA glucuronide have increased in nontransplant individuals with severe chronic renal impairment (GFR $<25 \mathrm{~mL} /$ minute per $1.73 \mathrm{~m}^{2}$ ). Plasma MPA concentrations in patients with delayed graft function similar to values in patients not experiencing delayed graft function. In hereditary deficiency of hypoxanthine-guanine phosphoribosyl-transferase (HGPRT), such as Lesch-Nyhan and Kelley-Seegmiller syndrome, the use of MPM (a inosine monophosphate dehydrogenase inhibitor) is not recommended (Ahsan et al., 1999).

\subsubsection{Effect of food consumption, ethnicity and sex}

Food delayed MPM absorption, the extent of absorption was not affected by food; however, the maximum concentration of the active metabolite was reduced by $40 \%$. Administration of MPA delayed release tablet with a high fat meal did not affect the extent of absorption of mycophenolic acid, but the maximal plasma concentration was reduced by $33 \%$, and there was a 5 hours delay in the time to reach maximal concentration (Bullingham et al. 1998). A pharmacokinetic study showed that the rate but not the extent of absorption of mycophenolate is affected by food, indicating that mycophenolate may be administered with food (Christians et al., 2010). 
Ethnicity and sex do not significantly affect the primary pharmacokinetic parameters of MPA. A study examine MPA pharmacokinetics in 13 African American and 20 Caucasian renal transplant recipients during the first 4 to 90 posttransplant days and found No significant differences in either MPA AUC or free MPA AUC values (Shaw et al., 2000). Another investigation compared MPA pharmacokinetics in 39 African American and 43 Caucasian renal allograft recipients with stable graft function, There were no significant differences in MPA AUC, Cmax and tmax values between the two groups (Pescovitz et al., 2003). MPA pharmacokinetic parameters did not differ significantly in the males versus females in this study. No differences between diabetic and nondiabetic stable renal transplant recipients were found in this study. Limited studies comparing pharmacokinetics parameters between African-American and white renal transplant patients have shown few differences, suggesting that the differences in rejection rates between these two populations are not explained by pharmacokinetic differences alone but are more likely related to differences in innate immunologic response (Ahsan et al., 1999).

\subsubsection{Relationship between adult and pediatric patients}

There was a considerable inter- and intraindividual variability of pharmacokinetic parameters in both patient groups. Some of this variability appears to be related to the function of the kidney transplant, because in patients with primary transplant dysfunction a bower maximal MPA concentration and a longer time to maximum concentration were observed. This may be due to slower absorption of MMF, most likely as a result of uremic dysmotility of the gastrointestinal tract (Halloran et al., 1997). Because for MMF there is a relationship between the immunosuppressive efficacy in renal transplant recipients and the MPA-AUC, this fact predict that MMF in a dose of $600 \mathrm{mg} / \mathrm{m}^{2}$ twice a day displays a comparable effectiveness in pediatric transplant recipients, as observed previously in adult patients. This hypothesis is currently being investigated in a large multicenter study. A dose of $600 \mathrm{mg}$ MMF/m2 BSA in children between the ages of 6 and 15 year yielded comparable AUC for MPA and free MPA at 3 weeks after renal transplantation as adults who received $1 \mathrm{~g}$ of MMF, the recommended twice daily oral dose in adults (Bullingham, 1996a). Hence, the body surface area (BSA) -adjusted dosing of MMF appears to be appropriate in pediatric renal transplant recipients. MPM pharmacokinetic parameters, including AUC, in children 1 to 18 years of age receiving MPM $600 \mathrm{mg} / \mathrm{m}^{2}$ (in oral suspension) twice daily following renal transplantation similar to values in adult renal transplant recipients receiving $1 \mathrm{~g}$ twice daily. MPS peak plasma concentrations and AUC of MPA in stable pediatric renal transplant patients 5 to 16 years of age receiving a single dose of MPS (MPA $450 \mathrm{mg} / \mathrm{m}^{2}$ ) increased (33 and 18\% respectively) relative to adults receiving the same dose based on body surface area. Clinical importance is not determined yet (Halloran et al., 1997).

\subsection{Effect of time after transplantation on MPA Pharmacokinetics}

The dose-interval MPA AUC in renal transplant recipients increases as a function of time. The dose-normalized mean MPA AUC in renal transplant patients is at least 30 to $50 \%$ lower in the first few weeks after transplantation than in the later period (1-6 months after transplantation). It has been demonstrated that most of this phenomenon is accounted for in the novo renal transplant patients with impaired renal function. The reason for lower MPA AUC in this patients in the early posttransplant compared with the time when graft 
function has stabilized (about 1 month after transplant surgery) is most likely the decreased plasma protein binding of MPA leading to an increase clearance of drug by the liver (Shaw et al., 1998). This theory is supported by observations of elevated free MPA fraction values in the early posttransplantation period in patients with impaired renal function that return to normal values by 1 month posttransplantation. A possible additional factor that could contribute to the higher oral clearance of MPA early after transplantation is corticosteroid therapy, which is significantly higher in that period but then is tapered to low dose levels or completely withdrawn. In pediatric patients, as in adult subjects, the median AUC values increase as a function of time after transplantation (from approximately $35 \mathrm{mg} . \mathrm{h} / \mathrm{L}$ at weeks to approximately $65 \mathrm{mg} . \mathrm{h} / \mathrm{L}$ at 3 months after transplantation). The intraindividual variability of AUC was high in the immediate posttransplant period, but decline in the stable phase, whereas the wide interindividual variability remained significant (Oellerich et al., 2000).

\subsection{Pharmacokinetic Interactions with mycophenolate mofetil}

Since mycophenolate mofetil is solely metabolized by glucuronidation, direct pharmacokinetic interactions with drugs metabolised by cytochrome P450 oxidation are not generally expected. Pharmacokinetic interaction with other drugs metabolised by glucuronidation is a theoretical possibility, although a clinically significant interaction is very unlikely. Potential general mechanisms for interactions with mycophenolate mofetil involve either entrohepatic cycling, or renal tubular competition between MPAG and other drugs undergoing transport mediated renal excretion. As regards the former, competitive interaction could occur between MPAG and other drugs at the biliary transporter, although no example has been reported. Once MPAG is excreted into the gut, cholestyramine and other bile acid sequestrants can clearly reduce the plasma mycophenolic acid AUC and hence clinical effectiveness. Deglucuronidation of MPAG in the colon is mediated by the gut flora, and in particular by the Gram-negative anaerobes which contain most of the glucuronidase activity. Antibiotics with activity against such organisms may reduce entrohepatic cycling and hence the mycophenolic acid AUC. With a renal tubular interaction, plasma mycophenolic acid is not affected. No major clinical sequelae appear to follow from raised plasma MPAG concentrations. The clinical significance of any tubular interaction will thus depend on the magnitude and consequence of raised plasma concentrations of the other interacting drug. Being a competitive interaction, high plasma MPAG concentrations are likely to increase the magnitude of the interaction. Renal impairment may thus be the clinical situation where such interactions need special consideration (Bullingham et al. 1998).

\subsection{Clinical efficacy}

The relationship between MPA pharmacokinetics and clinical outcomes has been reported in at least 1o investigations. The association between MPA AUC and the risk for acute rejection was first noted in a retrospective analysis of pharmacokinetic data obtained during the first 3 weeks after transplantation, in a dose-escalation study of MMF in 41 adult kidney transplant patients (Jeong \& Kaplan, 2007; Takahashi et al., 1995). In mid-1990s, three large clinical trials were conducted in kidney transplant recipients to prove clinical efficacy of MMF. These were the largest prospective, randomized, double blind trials ever performed in transplantation, using the incidences of acute rejection as a primary end point. The results 
demonstrated the superior efficacy of MMF (1.0 or $1.5 \mathrm{~g}$ twice daily), combined with cyclosporine and steroids, in reducing the rate of acute rejection during 6 months after kidney transplantation as compared with azathioprine or placebo treatment (Jeong \& Kaplan, 2007). Also, they established the safety of MMF in adult renal transplant patients; overall incidence of adverse effects was comparable between groups. The prominent adverse effects of MMF included nausea, vomiting, diarrhea, and hematologic effects, with a high dosage $(3 \mathrm{~g} / \mathrm{d})$ being associated with increased risk for the adverse effects. Subsequent long-term (1- and 3-years) follow-up studies reported the similar efficacy and safety of MMF. Other maintenance immunosuppressants that have been evaluated in combination with MMF include tacrolimus. A randomized, clinical trial in renal transplant patients who were treated with tacrolimus-based triple regimens (tacrolimus/MMF/steroid) demonstrated a significant reduction in the incidence of rejection compared with the double regimen group when MMF was given at a dosage of $1 \mathrm{~g}$ twice a day for 1 year after transplantation. However, in the first 6 months of this trial, MMF was discontinued in half of the patients because of gastrointestinal complications or hematologic adverse effects, indicating the need for lower MMF dosages. It was understood later to be because tacrolimus does not inhibit biliary excretion of MPAG, whereas cyclosporine disrupts enterohepatic cycling and intestinal reabsorption of MPA by inhibiting biliary transporters. Subsequent monitoring of MPA levels in renal transplant patients revealed that MPA plasma levels were lower in the cyclosporine-based regimen compared with the tacrolimus combination. In conclusion, MMF is effective in preventing acute rejection and improving graft and patient survival in combination with cyclosporine and tacrolimus. Tacrolimusbased treatment requires a lower dosage of MMF compared with a cyclosporine-based regimen to maintain the similar MPA plasma levels. (Pawinski et al., 2006).

\subsection{Therapeutic drug monitoring}

The incorporation of MMF into immunosuppressive regimens has been associated with decreased rates of acute rejection and decreased chronic allograft loss. When the drug was introduced into clinical practice, routine therapeutic drug monitoring was not recommended and empiric dosing became the norm of many centers. However, a deeper appreciation for the highly variable pharmacokinetic behavior of MPA and the relationship between concentration of the drug and risk for acute rejection, combined with an increased emphasis on the need for further improvements in clinical outcomes, treatment of patients with greater risk for graft loss than ever before, and the use of strategies for lowering or eliminating concomitant agents such as corticosteroids or CNI, have led to increasing interest in the role of MPA therapeutic drug monitoring in optimizing immunosuppression. Recent reviews have suggested provisional target therapeutic ranges for MPA AUC and trough concentrations when using MMF in combination with either cyclosporine or tacrolimus. When combined with cyclosporine, the recommended target ranges are 1 to 3.5 $\mathrm{mg} / \mathrm{L}$ and 30 to $60 \mathrm{mg} / \mathrm{h}$ per $\mathrm{L}$ for trough concentrations and AUC, respectively. For the combination with tacrolimus, the target ranges of 1.9 to $4.0 \mathrm{mg} / \mathrm{L}$ and 30 to $60 \mathrm{mg} / \mathrm{h}$ per L for trough and AUC measurements, respectively, have been suggested (Van Gelder et al., 2006). Two ongoing concentration-control versus fixed dosage trials in renal transplant patients will hopefully provide the basis for rigorous assessment of these target ranges in the setting of contemporary practice. A proposed schedule for objective assessment of MPA exposure is presented in Table 4 . We hope that the ongoing trials will provide more 
definitive data on which to base the selection of sample type, test schedule, and the costbenefit analysis of MPA therapeutic monitoring (Shaw et al., 2007).

\section{Corticosteroids}

\subsection{Mechanism of action}

Glucocorticoids exert their effects by binding to a glucocorticoid receptor (GR) localized in the cytoplasm of target cells. There is a single class of GR that binds glucocorticoids, with no evidence for subtypes of differing affinity in different tissues. Recently a splice variant of GR, termed GR-b, has been identified that does not bind glucocorticoids but binds to DNA and may therefore potentially interfere with the action of glucocorticoids (Bamberger et al., 1995).

\subsection{Pharmacokinetics}

The pharmacokinetic characteristics of the various glucocorticoids depend on their physicochemical properties. Glucocorticoids are lipophilic and are usually administered as prodrugs when given intravenously (Mager \& Jusko, 2002).

\subsubsection{Absorption and distribution}

Glucocorticoids are well absorbed after oral administration and have a bioavailability of 60 $100 \%$. They have moderate protein binding and a moderate apparent volume of distribution (Derendorf et al., 1991; Varis et al., 2000). Over 90\% of circulating plasma corticosteroids attached to two types of proteins: (1) a non-specific albumin, and (2) a high affinity transcortin, an $\alpha$-2-globulin important in regulating corticosteroid flowing freely, as allows greater freedom in tissues with an inflammatory response. Transcortin has a high affinity and a low capacity for hydrocortisone and prednisolone, whereas albumin has a low affinity but high capacity. This leads to an increase in the free glucocorticoid fraction once transcortin is saturated at concentrations of about $400 \mu \mathrm{g} / \mathrm{L}$. Such concentrations are achieved after administration of hydrocortisone or prednisolone doses $>20 \mathrm{mg}$ (Czock et al., 2005). Protein binding is biologically relevant, because only free drug can reach the biophase (i.e. the site of action) and interact with the receptor. Therefore, pharmacodynamic considerations have to include protein binding. Clinically, decreased protein binding due to low plasma albumin concentrations correlated with glucocorticoid adverse effects in prednisone therapy (Lewis et al., 1971). Generally, however, alterations in protein binding do not have much impact on drug action (Benet et al., 2002; Czock et al., 2005).

\subsubsection{Metabolism and excretion}

The renal excretion of unchanged glucocorticoids is only 1-20\% (Garg \& Jusko, 1994). Glucocorticoid metabolism is a two-step process. Firstly, oxygen or hydrogen atoms are added then secondly, conjugation takes place (glucuronidation or sulphation). Subsequently the kidney excretes the resulting hydrophilic inactive metabolites. Intracellular metabolism by $11 \beta$-hydroxysteroid dehydrogenase (11 $\beta$-HSD) controls the availability of glucocorticoids for binding to the glucocorticoid and mineralocorticoid receptors. Type 1 dehydrogenase $(11 \beta-H S D 1)$ is widely distributed in glucocorticoid target tissues and has its highest activity in the liver. 11 $\beta$-HSD1 acts mainly as a reductase, converting the inactive cortisone to the active cortisol (Czock et al., 2005). Type 2 dehydrogenase (11 $\beta$-HSD2) is found in 
mineralocorticoid target tissues (kidney, colon, salivary glands, placenta). 11 $\beta-H S D 2$ has a high affinity for endogenous cortisol and by oxidation, converting cortisol to cortisone, it protects the mineralocorticoid receptor from occupation by cortisol. The activity of $11 \beta-$ HSD2 varies depending on the type of glucocorticoid, which explains to some extent the different mineralocorticoid activities of different glucocorticoids (Diederichet al., 2002).

\subsubsection{Prednisolone and prednisone}

The pharmacokinetics of prednisolone and prednisone are complicated by dose-dependency due to nonlinear protein binding (Wald et al., 1992). Protein binding of prednisolone decreases nonlinearly from $95 \%$ to $60-70 \%$, while the concentration increases from 20060 $70 \%$, while the concentration increases from $200 \mu \mathrm{g} / \mathrm{L}$ to $800 \mu \mathrm{g} / \mathrm{L}$ when protein binding of prednisolone reaches the stationary state (Rose et al., 1981). In consequence, a dosedependent increase in the volume of distribution $(\mathrm{Vd})$ and drug clearance $(\mathrm{CL})$ is observed at doses over 20mg (Frey et al., 1990; Rohatagi et al., 1997). However, the elimination halflife remains constant and the dose dependencies of $\mathrm{Vd}$ and $\mathrm{CL}$ disappear when free prednisolone concentrations are measured (Möllmann et al., 1989; Rohatagi 1997). Prednisolone clearance decreases again only at very high doses, which can be explained by saturation of elimination mechanisms. The affinity of prednisone for transcortin is 10-fold lower than that of prednisolone (Czock et al., 2005).

\subsubsection{Methylprednisolone}

Methylprednisolone (6a-methylprednisolone) has no affinity for transcortin and binds only to albumin (Czock et al., 2005). Accordingly, methylprednisolone pharmacokinetics are linear, with no dose-dependency. The disposition of methylprednisolone is biexponential (Möllmann et al., 1989). A two-compartment model is appropriate for intravenous administration of very high doses. A one compartment model can be used with lower intravenous doses and oral administration (Booker et al., 2002; Lewis et al. 1971).

\subsection{Interactions between glucocorticoids and tacrolimus}

Corticosteroids are an essential component of most immunosuppressive regimens currently used in renal transplantation because of their efficacy in reducing acute rejection and improving graft survival. The precise mechanism of action of glucocorticoids is not fully understood, although it is apparent that it is multifaceted, involving both direct and indirect mechanisms and affecting proximal and distal events of $\mathrm{T}$ cell activation (Almawi et al., 1999). Long-term administration of corticosteroids also is known to be associated with numerous adverse effects that lead to increased patient morbidity and mortality after renal transplantation. The adverse effects of corticosteroids, including new-onset diabetes, hyperlipidemia, hypertension, growth retardation, accelerated bone loss, weight gain, avascular necrosis, cataracts, cosmetic changes, depression, psychotic behavior, and others, have been well documented Hricik et al., 1993; Grotz et al., 1998; Kobashigawa \& Kasiske, 1997; Schulak \& Hricik, 1994). There also is evidence that they may interfere with the tolerogenic pathways of organ acceptance (Qian et al., 1997; Wang et al., 2001). In addition to affecting the morbidity and the quality of life of renal transplant recipients, corticosteroids increase the long-term cost of their medical. Because glucocorticoids are inducers of the CYP34A4 enzyme involved in tacrolimus metabolism, theoretically glucocorticoid use would be expected to necessitate increased tacrolimus dosing. Indeed, 
studies in adults have documented increased tacrolimus levels upon steroid withdrawal, but similar data on pediatric patients are not available. In recent years, tacrolimus has been used both steroid based and steroid-free immunosuppressive protocols (van Duijnhoven et al., 2003; Anglicheau et al., 2003). Steroid avoidance or rapid elimination of steroids may have an advantage over steroid withdrawal. Steroid avoidance protocols may avoid the long-term risks of steroid use and the increased risk for rejection when the steroids are withdrawn. Birkeland and Khwaja reported excellent long term graft survival and function ( 3 and 4 year, respectively) with very low rejection rates. In other studies, a slight increase in acute rejection episodes, especially in the early posttransplantation period, was observed; these were easily reversible, and their impact on long-term graft survival is unclear at this time (Borrows et al., 2004; Cole et al., 2001; Grewal et al., 1998; ter Meulen et al., 2004). Steroids, once thought to be a mandatory component of immunosuppression to preserve graft survival, are gradually being eliminated from current protocols. It has long been recognized that despite the efficacy of maintenance corticosteroids that these medications are far from benign (Jaber et al., 2007). Consequently, corticosteroid-free immunosuppression has become a desirable goal for many in the transplant community. A potential problem of eliminating corticosteroids from an immunosuppressive regimen, however, is an increased risk for acute rejection (Vanrenterghem et al., 2000).

\section{References}

Ahsan, N., Hricik, D., \& Matas, A., Rose, S., Tomlanovich, S., \& Wilkinson, A., Ewell, M., McIntosh, M., \& Stablein, D., Hodge E. Prednisone withdrawal in kidney transplant recipients on cyclosporine and mycophenolate mofetil--a prospective randomized study. Steroid Withdrawal Study Group. Transplantation, Vol. 68, No. 12, (December 1999), pp. 1865-1874, ISSN 1534-0608

Almawi, W.Y., Melemedjian, O.K., \& Rieder, M.J. An alternate mechanism of glucocorticoid anti-proliferative effect: Promotion of a Th2 cytokine-secreting profile. Clinical Transplantation, Vol. 13, No. 5, (October 1999), pp. 365-374, ISSN 0902-0063

Anglicheau, D., Flamant, M., \& Schlageter, M.H., Martinez, F., Cassinat, B., \& Beaune, P., Legendre, C., \& Thervet, E. Pharmacokinetic interaction between corticosteroids and tacrolimus after renal transplantation. Nephrology Dialysis Transplantation, Vol. 18, No. 11, (November 2003), pp. 2409-14, ISSN 1460-6235

Bai, J.P., Lesko, L.J., \& Burckart, G.J. Understanding the genetic basis for adverse drug effects: the calcineurin inhibitors. Pharmacotherapy, Vol. 30, No. 2, (February 2010), pp. 195-209, ISSN 0277-0008

Bamberger, C.M., Bamberger, A.M., \& de Castro, M., Chrousos, G.P. Glucocorticoid receptor beta, a potential endogenous inhibitor of glucocorticoid action in humans. Journal of Clinical Investigation, Vol. 95, No. 6, (Jun 1995), pp. 2435-2441, ISSN 0021-9738

Barrera-Pulido, L., Aguilera-García, I., \& Docobo-Pérez, F., Alamo-Martínez, J.M., \& ParejaCiuró, F., Nuñez-Roldán, A., \& Gómez-Bravo, M.A., Bernardos-Rodríguez, A. Clinical relevance and prevalence of polymorphisms in CYP3A5 and MDR1 genes that encode tacrolimus biotransformation enzymes in liver transplant recipients. Transplantation Proceedings, Vol. 40, No. 9, (November 2008), pp. 2949-2951, ISSN 0041-1345 
Bekersky, I., Dressler, D., \& Mekki, Q. Effect of time of meal consumption on bioavailability of a single oral $5 \mathrm{mg}$ tacrolimus dose. Journal of Clinical Pharmacology, Vol. 41, No. 3, (March 2001), pp. 289-297, ISSN 1552-4604

Bekersky, I., Dressler, D., \& Mekki, Q.A. Effect of low- and high-fat meals on tacrolimus absorption following $5 \mathrm{mg}$ single oral doses to healthy human subjects. Journal of Clinical Pharmacology, Vol. 41, No. 2, (February 2001), pp. 176-182, ISSN 1552-4604

Benet, L.Z. \& Hoener B.A. Changes in plasma protein binding have little clinical relevance. Clinical Pharmacology and Therapeutics, Vol. 71, No. 3, (March 2002), pp. 115-121, ISSN 0009-9236

Birkeland, S.A. Steroid-free immunosuppression in renal transplantation: A long-term follow-up of 100 consecutive patients. Transplantation, Vol.71 , No. 8, (April 2007), pp. 1089-90, ISSN 1534-0608

Booker, B.M., Magee, M.H., \& Blum, R.A., Lates, C.D., Jusko, W.J. Pharmacokinetic and pharmacodynamic interactions between diltiazem and methyl prednisolone in healthy volunteers. Clinical Pharmacology and Therapeutics, Vol. , No. , (October 2002), pp. 370-382, ISSN 0009-9236

Borrows, R., Loucaidou, M., \& Van Tromp, J., Cairns, T., Griffith, M., \& Hakim, N., McLean, A., Palmer, A., \& Papalois, V., Taube, D. Steroid sparing with tacrolimus and mycophenolate mofetil in renal transplantation. American Journal of Transplantation, Vol. 4, No. 11, (November 2004), pp. 1845-51, ISSN 1600-6143

Bullingham, R., Monroe, S., \& Nicholls, A., Hale, M. Pharmacokinetics and bioavailability of mycophenolate mofetil in healthy subjects after single-dose oral and intravenous administration. Journal of Clinical Pharmacology, Vol. 36, No. 4, (April 1996b), pp. 315-324, ISSN 1552-4604

Bullingham, R., Nicholls, A., \& Hale, M. Pharmacokinetics of mycophenolate mofetil (RS 61443): A short review. Transplantation Proceedings, Vol. 28, No. 2, (April 1996a), pp. 925-929, ISSN 0041-1345

Bullingham, R.E., Nicholls, A.J., Kamm, .BR. Clinical pharmacokinetics of mycophenolate mofetil. Clinical Pharmacokinetics, Vol. 34, No. 6, (1998), pp. 429-455, ISSN 03125963

Cattaneo, D., Perico, N., \& Remuzzi, G. From pharmacokinetics to pharmacogenomics: a new approach to tailor immunosuppressive therapy. American Journal of Transplantation, Vol. 4, No. 3, (March 2004), pp. 299-310, ISSN 1600-6143

Chen, J.S., Li, L.S., \& Cheng, D.R., Ji, S.M., \& Sun, Q.Q., Cheng, Z., \& Wen, J.Q., Sha, G.Z., \& Liu ZH. . Effect of CYP3A5 genotype on renal allograft recipients treated with tacrolimus. Transplantation Proceedings, Vol. 41, No. 5, (June 2002), pp. 1557-6, ISSN 0041-1345

Christians, U., Jacobsen, W., \& Benet, L.Z., Lampen, A. Mechanisms of clinically relevant drug interactions associated with tacrolimus. Clinical Pharmacokinetics, Vol. 41, No. 11, (2002), pp. 813-51, ISSN 0312-5963

Christians, U., Klawitter, J., \& Clavijo, C.F. Kidney International, Supplement, No.115, (March 2010), pp. S1-S7, ISSN 0085-2538

Christians, U., Pokaiyavannichkul, T., \& Chan, L. (2006). Tacrolimus, In: Applied Pharmacokinetics and Pharmacodynamics, Principles of Therapeutic Drug Monitoroing, M.E. Burton, L.M. Shaw, J.J. Schentag, W.E. Evans, (Ed.), pp. 529-562, Lippincott, Williams and Wilkins, ISSN 0-7817-4431-8, Philadelphia, United States of America 
Cole, E., Landsberg, D., \& Russell, D., Zaltzman, J., \& Kiberd, B., Caravaggio, C., and Vasquez, A.R., Halloran, P. A pilot study of steroid-free immunosuppression in the prevention of acute rejection in renal allograft recipients. Transplantation, Vol. 72, No. 5, (September 2001), pp. 845-50, ISSN 1534-0608

Czock, D., Keller, F., \& Rasche, F.M., Häussler, U. Pharmacokinetics and pharmacodynamics of systemically administered glucocorticoids. Clinical Pharmacokinetics, Vol. 44, No. 1, (2005), pp. 61-98, ISSN 0312-5963

Danesi, R., Mosca, M., \& Boggi, U., Del Tacca, M. Genetics of drug response to immunosuppressive treatment and prospects for personalized therapy. Molecular Medicine Today, Vol. 6, No. 12, (December 2000), pp. 475-482. [Abstract] ISSN 13574310

del Mar Fernández De Gatta, M., Santos-Buelga, D., \& Domínguez-Gil, A.,García, M.J. Immunosuppressive therapy for paediatric transplant patients: pharmacokinetic considerations. Clinical Pharmacokinetics, Vol. 41, No. 2 (2002), pp. 115-135, ISSN 0312-5963

Derendorf, H., Möllmann, H., \& Barth, J., Möllmann, C., \& Tunn, S., Krieg, M. Pharmacokinetics and oral bioavailability of hydrocortisone. Journal of Clinical Pharmacology, Vol. 31, No. 5, (May 1991), pp. 473-476, ISSN 1552-4604

Diederich, .S, Eigendorff, E., \& Burkhardt, P., Quinkler, M., \& Bumke-Vogt, C., Rochel, M., \& Seidelmann, D., Esperling, P., \& Oelkers, W., Bähr, V. $11 \beta$-hydroxysteroid dehydrogenase types 1 and 2: an important pharmacokinetic determinant for the activity of synthetic mineralo- and glucocorticoids. The Journal of Clinical Endocrinology and Metabolism, Vol. 87, No. 12, (December 2002), pp. 5695- 5701, ISSN 1945-7197

Dresser, G.K., Spence, J.D., \& Bailey, D.G. Pharmacokinetic-pharmacodynamic consequences and clinical relevance of cytochrome P450 3A4 inhibition. Clinical Pharmacokinetics, Vol. 38, No. 1, (2000), pp. 41-57, ISSN 0312-5963

Felipe, C.R., Silva, H.T., \& Machado, P.G., García, R., \& da Silva Moreira, S.R., Pestana, J.O. The impact of ethnic miscegenation on tacrolimus clinical pharmacokinetics and therapeutic drug monitoring. Clinical Transplantation, Vol. 16, No. 4, (August 2002), pp. 262-272, ISSN 0902-0063

Fitzsimmons, W.E., Bekersky, I., \& Dressler, D., Raye, K., \& Hodosh, E., Mekki, Q. Demographic considerations in tacrolimus pharmacokinetics. Transplantation Proceedings, Vol. 30, No. 4, (June 1998), pp. 1359-1364, ISSN 0041-1345

Frey, B.M. \& Frey, F.J. Clinical pharmacokinetics of prednisone and prednisolone. Clinical Pharmacokinetics, Vol. 19, No. 2, (1990), pp. 26-46, ISSN 0312-5963

Fung, J.J. Tacrolimus and transplantation: A decade in review. Transplantation, Vol. 77, No. 9, (May 2004), pp. S41-S43, ISSN 1534-0608

Garg, V. \& Jusko, W.J. Bioavailability and reversible metabolism of prednisone and prednisolone in man. Biopharmaceutics and Drug Disposition, Vol. 15, No. 2, (March 1994), pp. 163-172, ISSN 0142-2782

González-Posada, J.M., Hernández, D., \& Bayés Genís, B., García Perez, J., \& Rivero Sanchez M. Impact of diabetes mellitus on kidney transplant recipients in Spain. Nephrology Dialysis Transplantation, Vol. 19, No. S3, (June 2004), pp. iii57-61, ISSN 1460-6235

Grewal, H.P., Thistlethwaite, J.R. Jr., \& Loss, GE. Corticosteroid cessation 1 week following renal transplantation using tacrolimus/mycophenolate mofetil based 
immunosuppression. Transplantation Proceedings, Vol. 30, No. 4, (June 1998), pp. 1378-1379, ISSN 0041-1345

Grotz, W.H., Rump, L.C., \& Niessen, A., Schmidt-Gayk, H., \& Reichelt, A., Kirste, G., \& Olschewski, M., Schollmeyer, P.J. Treatment of osteopenia and osteoporosis after kidney transplantation. Transplantation, Vol. 66, No. 8, (October 1998), pp. 10041008, ISSN 1534-0608

Halloran, P., Mathew, T., \& Tomlanovich, S., Groth, C., Hooftman, L., \& Barker, C. Mycophenolate mofetil in renal allograft recipients: a pooled efficacy analysis of three randomized, double-blind, clinical studies in prevention of rejection. Transplantation, Vol. 63, No. 1, (January 1997), pp. 39-47, ISSN 1534-0608

Halloran, P.F. Immunosuppressive Drugs for Kidney Transplantation. New England Journal of Medicine, Vol. 351, No. 26, (December 2002), pp. 2715-2729, ISSN 0028-4793

Hämmerlein, A., Derendorf, H., \& Lowenthal, D.T. Pharmacokinetic and pharmacodynamic changes in the elderly. Clinical implications. Clinical Pharmacokinetics, Vol. 35, No. 1, (2002), pp. 49-64, ISSN 0312-5963

Hariharan, S., Schroeder, T.J., \& First, M.R. Effect of race on renal transplant outcome. Clinical Transplantation, Vol. 7, No. 3, (June 1993), pp. 235, ISSN 0902-0063

Harris, R.Z., Benet, L.Z., \& Schwartz, J,B. Gender effects in pharmacokinetics and pharmacodynamics. Drugs, Vol. 50, No. 2, (2002), pp. 222-239, ISSN 0012-6667

Hebert, M.F., Fisher, R.M., \& Marsh, C.L., Dressler, D., \& Bekersky, I. Effects of rifampin on tacrolimus pharmacokinetics in healthy volunteers. Journal of Clinical Pharmacology, Vol. 39, No. 1, (February 1999), pp. 91-96, ISSN 1552-4604

Hesselink, D.A., Bouamar, R., \& van Gelder, T. The pharmacogenetics of calcineurin inhibitor-related nephrotoxicity. Therapeutic Drug Monitoring, Vol. 32, No. 4, (August 2010), pp. 387-393, ISSN 0163-4356

Hesselink, D.A., Ngyuen, H., \& Wabbijn, M., Gregoor, P.J., Steyerberg, E.W., \& van Riemsdijk, I.C., Weimar, W., \& van Gelder T. Tacrolimus dose requirement in renal transplant recipients is significantly higher when used in combination with corticosteroids. British Journal of Clinical Pharmacology, Vol. 56, No. 3, (September 2003), pp. 327-30, ISSN 1552-4604

Hricik, D.E., O'Toole, M.A., \& Schulak, J.A., Herson, J. Steroid-free immunosuppression in cyclosporine treated renal transplant recipients: a meta-analysis. Journal of the American Society of Nephrology, Vol. 4, No. 6, (December 1993), pp. 1300-1005, ISSN 1046-6673

Hübner, G.I., Eismann, R., \& Sziegoleit, W. Drug interaction between Mycophenolate mofetil and tacrolimus detectable within therapeutic mycophenolic acid monitoring in renal transplant recipients. Therapeutic Drug Monitoring, Vol. 21, No. 5, (October 199), pp. 536-539, ISSN 0163-4356

Iwasaki, K. Metabolism of Tacrolimus (FK506) and Recent Topics in Clinical Pharmacokinetics. Drug Metabolism and Pharmacokinetics, Vol. 22, No. 5, (October 2007), pp. 328-335, ISSN 1347-4367

Jaber, J.J., Feustel, P.J., \& Elbahloul, O., Conti, A.D., \& Gallichio, M.H., Conti, D.J. Early steroid withdrawal therapy in renal transplant recipients: a steroid-free sirolimus and CellCept-based calcineurin inhibitor-minimization protocol. Clinical Transplantation, Vol. 21, No. 1, (January-February 2007), pp. 101-109, ISSN $0902-$ 0063 
Jeong, H. \& Kaplan, B. Therapeutic monitoring of mycophenolate mofetil. Clinical Journal of the American Society of Nephrology, Vol. 2, No. 1, (January 2007), pp. 184-191, ISSN 1555-9041

Johnson, A.G., Rigby, R.J., \& Taylor, P.J., Jones, C.E., Allen, J., \& Franzen, K., Falk, M,C., \& Nicol, D. The kinetics of mycophenolic acid and its glucuronide metabolite in adult kidney transplant recipients. Clinical Pharmacology and Therapeutics, Vol. 66, No. , (November 1999), pp. 492-500, ISSN 0009-9236

Joy, M.S., Hogan, S.L., \& Thompson, B.D., William, F., \& Finn, W.F., Nickeleit, V. Cytochrome P450 3A5 expression in the kidneys of patients with calcineurin inhibitor nephrotoxicity. Nephrology Dialysis Transplantation, Vol. 22, No. 7, (July 2007), pp. 1963-1968, ISSN 1460-6235

Jusko, W.J. Analysis of tacrolimus (FK 506) in relation to therapeutic drug monitoring. Therapeutic Drug Monitoring, Vol. 17, No. 6, (December 1995), pp. 596-601, ISSN 0163-4356

Jusko, W.J. \& Kobayashi, M. Therapeutic monitoring of tacrolimus (FK 506). Therapeutic Drug Monitoring, Vol. 15, No. 4, (August 1993), pp. 349, ISSN

Jusko, W.J., Thomson, A.W., \& Fung, J., McMaster, P., \& Wong, S.H., Zylber-Katz E. Consensus document: therapeutic monitoring of tacrolimus (FK506). Therapeutic Drug Monitoring, Vol. 17, No. 6, (December 1995), pp. 606-614, ISSN 0163-4356

Kamar, N., Mariat, C., \& Delahousse, M., Dantal, J., Al Najjar, A., \& Cassuto, E., Lefrançois, N., Cointault, O., \& Touchard, G., Villemain, F., \& Di Giambattista, F., Benhamou, P.Y. Diabetes mellitus after kidney transplantation: a French multicentre observational study. Nephrology Dialysis Transplantation, Vol. 22, No. 7, (July 2007), pp. 1986-1993, ISSN 1460-6235

Kaplan, B., Meier-Kriesche, H.U., \& Friedman, G., Mulgaonkar, S., Gruber, S., \& Korecka, M., Brayman, K.L., Shaw, L.M. Pharmacokinetics of mycophenolic acid in renal transplant patients whit delayed graft function. Journal of Clinical Pharmacology. 1998;39(7):715-20

Kapturczak, M.H., Meier-Kriesche, H.U., \& Kaplan, B. Pharmacology of calcineurin antagonists. Transplantation Proceedings, Vol. 36, No. 2S, (March 2004), pp. 25S-32S, ISSN 0041-1345

Khwaja, K., Asolati, M., \& Harmon, J., Melancon, J.K., \& Dunn, T., Gillingham, K., \& Kandaswamy, R., Humar, A., \& Gruessner, R., Payne, W., \& Najarian, J., Dunn, D., \& Sutherland, D., Matas AJ. Outcome at 3 years with a prednisone-free maintenance regimen: A single-center experience with 349 kidney transplant recipients. American Journal of Transplantation, Vol. 4, No. 6, (June 2004), pp. 980-987, ISSN 1600-6143

Kiberd, B.A., Lawen, J., \& Fraser, A.D., Keough-Ryan, T., \& Belitsky, P. Early adequate mycophenolic acid exposure is associated with less rejection in kidney transplantation. American Journal of Transplantation, Vol. 4, No. 7, (July 2004), pp. 1079-1083, ISSN 1600-6143

Kobashigawa, J.A. \& Kasiske, B.L. Hyperlipidemia in solid organ transplantation. Transplantation, Vol. 63, No. 3, (February 1997), pp. 331-338, ISSN 1534-0608

Lewis, G.P., Jusko, W.J., \& Graves, L., ND Burke, C.W. Prednisone side-effects and serumprotein levels: a collaborative study. The Lancet, Vol. 2, No. 7728, (October 1971), pp. 778-780, ISSN 0140-6736 
López-Montenegro Soria, M.A., Kanter Berga, J., \& Beltrán Catalán, S., Milara Payá, J., \& Pallardó Mateu, LM., Jiménez Torres, N.V. Genetic Polymorphisms and Individualized Tacrolimus Dosing. Transplantation Proceedings, Vol. 42, No. 8, (October 2010), pp. 3031-3033, ISSN 0041-1345

Lown, K.S., Mayo, R.R., \& Leichtman, A.B., Hsiao, H.L., \& Turgeon, D.K., Schmiedlin-Ren, \& P., Brown, M.B., Guo, W., \& Rossi, S.J., Benet, L.Z., \& Watkins, P.B. Role of intestinal P-glycoprotein (MDR1) in interpatient variation in the oral bioavailability of cyclosporine. Clinical Pharmacology and Therapeutics. Vol. 62, No.3 , (September 1997), pp. 248-260, ISSN 0009-9236

Macphee, I.A., Fredericks, S., \& Mohamed, M., Moreton, M., \& Carter, N.D., Johnston, A., \& Goldberg, L., Holt, D.W. Tacrolimus pharmacogenetics: the CYP3A5*1 allele predicts low dose-normalized tacrolimus blood concentrations in whites and South Asians. Transplantation, Vol. 79 , No. 4, (February 2002), pp. 499-502, ISSN 15340608

Macphee, I.A., Fredericks, S., \& Tai, T., Syrris, P., \& Carter, N.D., Johnston, A., \& Goldberg, L., Holt, D.W. Tacrolimus pharmacogenetics: polymorphisms associated with expression of cytochrome p4503A5 and P-glycoprotein correlate with dose requirement. Transplantation, Vol. 74, No. 11, (December 2002), pp. 1486-1489, ISSN 1534-0608

Mager, D.E. \& Jusko W.J. Quantitative structure-pharmacokinetic/pharmacodynamic relationships of corticosteroids in man. Journal of Pharmaceutical Sciences, Vol. 91, No. 11, (November 2002), pp. 2441-2451, ISSN 0022-3549

Mancinelli, L.M., Frassetto, L., \& Floren, L.C., Dressler, D., \& Carrier, S., Bekersky, I., \& Benet, L.Z., Christians, U. The pharmacokinetics and metabolic disposition of tacrolimus: a comparison across ethnic groups. Clinical Pharmacology and Therapeutics, Vol. 69, No. 1, (January 2001), pp. 24-31, ISSN 0009-9236

Mañez, R., Martin, M., \& Raman, D., Silverman, D., \& Jain, A., Warty, V., \& Gonzalez-Pinto, I., Kusne, S., \& Starzl, T.E. Fluconazole therapy in transplant recipients receiving FK506. Transplantation. Vol. 57, No. 10, (May 2002), pp.1521-1523 , ISSN 1534-0608

Markell M. New-onset diabetes mellitus in transplant patients: pathogenesis, complications, and management. American Journal of Kidney Disease, Vol. 43, No. 6, (June 2004), pp. 953-965, ISSN 0272-6386

Meibohm, B., Beierle, I., \& Derendorf, H. How important are gender differences in pharmacokinetics? Clinical Pharmacokinetics, Vol. 41, No. 5, (2002), pp. 329-342, ISSN 0312-5963

Meier-Kriesche, H.U. \& Kaplan, B. Cyclosporine microemulsion and tacrolimus are associated with decreased chronic allograft failure and improved long-term graft survival as compared with Sandimmune. American Journal of Transplantation, Vol. 2, No. 1, (January 2002), pp. 100-104, ISSN 1600-6143

Meier-Kriesche, H.U., Shaw, L.M., \& Korecka, M., Kaplan, B. Pharmacokinetics of mycophenolic acid in renal insufficiency. Therapeutic Drug Monitoring, Vol. 22, No. 1, (February 2000), pp. 27-30, ISSN 0163-4356

Möllmann, H., Rohdewald, P., \& Barth, J., Verho, M., Derendorf H. Pharmacokinetics and dose linearity testing of methylprednisolone phosphate. Biopharmaceutics and Drug Disposition, Vol. 10, No. 5, (September-October 1989), pp. 453-64, ISSN 0142-2872 
Mourad, M., Wallemacq, P., \& König, J., de Frahan, E.H., \& Eddour, D.C., De Meye,r M., \& Malaise, J., Squifflet, J.P. Therapeutic monitoring of mycophenolate mofetil in organ transplant recipients. Is it necessary? Clinical Pharmacokinetics, Vol. 41, No. 3, (2002), pp. 319-327, ISSN 0312-5963

Naesens, M., Kuypers, D.R., \& Sarwal, M. Calcineurin Inhibitor Nephrotoxicity. Clinical Journal of the American Society of Nephrology, Vol. 4, No. 2, (February 2009), pp. 481$508,1555-9041$

Ochiai, T., Fukao, K., \& Takahashi, K., Endo, T., \& Oshima, S., Uchida, K., \& Yokoyama, I., Ishibashi, M., \& Takahara, S., Iwasaki, Y. Phase III study of FK 506 in kidney transplantation. Transplantation Proceedings, Vol. 27, No. 1, (February 1995), pp. 829833, ISSN 0041-1345

Oellerich, M., Shipkova, M., \& Schütz E., Wieland, E., Weber, L., \& Tönshoff, B., Armstrong, V.W. Pharmacokinetic and metabolic investigations of mycophenolic acid in pediatric patients after renal transplantation: implications for therapeutic drug monitoring. Therapeutic Drug Monitoring, Vol. 22 No. 1, (February 2000), pp. 20-26, ISSN 0163-4356

Op den Buijsch, R.A., Christiaans, M.H., \& Stolk, L.M., de Vries J.E., \& Cheung, C.Y., Undre, N.A., \& van Hooff, J.P., van Dieijen-Visser, \& M.P., Bekers, O. Tacrolimus pharmacokinetics: infuence of adenosine triphosphate-binding cassette B1 (ABCB1) and cytochrome (CYP) 3A polymorphisms. Fundamental \& Clinical Pharmacology, Vol. 21, No. 4, (August 2007), pp. 427-35, ISSN 0767-3891

Paine, M.F., Khalighi, M., \& Fisher, J.M., Shen, D.D., \& Kunze, K.L., Marsh, C.L., \& Perkins, J.D., Thummel, KE. Characterization of interintestinal and intraintestinal variations in human CYP3A dependant metabolism. The Journal of Pharmacology and Experimental Therapeutic, Vol. 283, No. 3, (December 1997), pp. 1552-1562, ISSN 0022-3565

Pascual, M., Theruvath, T., \& Kawai, T., Tolkoff-Rubin, N., \& Cosimi, A.B. Strategies to improve long-term outcomes after renal transplantation. New England Journal of Medicine, Vol. 346, No. 8, (February 2002), pp. 580-590, ISSN 0028-4793

Pawinski, T., Durlik, M., \& Szlaska, I., Urbanowicz, A., \& Majchrnak, J., Gralak, B. Comparison of mycophenolic acid pharmacokinetic parameters in kidney transplant patients within the first 3 months post-transplant. Journal of Clinical Pharmacy and Therapeutics, Vol. 31, No. 1, (February 2006), pp.27-34, ISSN 0009-9236

Pescovitz, M.D., Guasch, A., \& Gaston, R., Rajagopalan, P., \& Tomlanovich, S., Weinstein, S., \& Bumgardner, G.L., Melton, L., \& Ducray, P,S., Banken, L., \& Hall, J., Boutouyrie, B.X. Equivalent pharmacokinetics of mycophenolate mofetil in African-American and Caucasian male and female stable renal allograft recipients. American Journal of Transplantation, Vol. 3, No. 12, (December 2003), pp.1581-1586, ISSN 16006143

Pillans, P.I., Rigby, R.J., \& Kubler, P., Willis, C., \& Salm, P., Tett, S.E., \& Taylor, P.J. A retrospective analysis of mycophenolic acid and ciclosporin concentrations with acute rejection in renal transplant recipients. Clinical Biochemistry, Vol. 34, No. 1, (February 2001), pp. 77-81, ISSN 0009-9120

Platz, K.P., Eckhoff, D.E., \& Hullett, D.A., Sollinger, H.W. RS-61443 studies: review and proposal. Transplantation Proceedings, Vol. 23, No. 2S2, (April 2002), pp. 33-35, ISSN 0041-1345 
Plosker, G.L., \& Foster, R.H. Tacrolimus: a further update of its pharmacology and therapeutic use in the management of organ transplantation. Drugs, Vol. 59, No. 2, (2000), pp. 323-89, ISSN 0012-6667

Prograf Product Monograph Astellas Pharma Canada, Inc. Revision 2009.

Qian, S., Lu, L., \& Fu, F., Li, Y., \& Li, W., Starzl, T.E., \& Fung, J.J., Thomson, A.W. Apoptosis within spontaneously accepted mouse liver allografts: evidence for deletion of cytotoxic T cells and implications for tolerance induction. Journal of Immunology, Vol. 158, No. 10, (May 1997), pp. 4654-4661, ISSN 1550- 6606

Rohatagi, S., Barth, J., \& Möllmann, H., Hochhaus, G., \& Soldner, A., Möllmann, C., \& Derendorf $\mathrm{H}$. Pharmacokinetics of methylprednisolone and prednisolone after single and multiple oral administration. Journal of Clinical Pharmacology, Vol. 37, No. 10, (October 1997), pp. 916-925, ISSN 1552-4604

Rose, J.Q., Yurchak, A.M., \& Jusko, W.J. Dose dependent pharmaco kinetics of prednisone and prednisolone in man. Journal of Pharmacokinetics and Biopharmaceutics, Vol. 20, No. 6, (August 1981), pp. 389-417, ISSN 0090-466X

Rosso Felipe, C., de Sandes, T.V., \& Sampaio, E.L., Park, S.I., \& Silva, H.T. Jr., Medina, and Pestana, .JO. Clinical impact of polymorphisms of transport proteins and enzymes involved in the metabolism of immunosuppressive drugs. Transplantation Proceedings, Vol. 41, No. 5, (June 2009), pp. 1441-1455, ISSN 0041-1345

Salvadori, M., Holzer, H., \& de Mattos, A., Sollinger, H., \& Arns, W., Oppenheimer, F., \& Maca, J., Hall, M. Enteric-coated mycophenolate sodium is therapeutically equivalent to mycophenolate mofetil in de novo renal transplant patients. American Journal of Transplantation, Vol. 4, No. 2, (February 2004), pp. 231-236, ISSN 16006143

Schaeffeler, E., Eichelbaum, M., \& Brinkmann, U. Frequency of C3435T polymorphism of MDR1 gene in African people. The Lancet, Vol. 358, No. 9279, (August 2001), pp. 383-384, ISSN 0140-6736

Schulak, J.A., \& Hricik DE. Steroid withdrawal after renal transplantation. Clinical Transplantation, Vol. 8, No. 2 Pt 2, (April 1994), pp. 211-216, ISSN 0902-0063

Schweitzer, E.J., Yoon, S., \& Fink, J., Wiland, A., \& Anderson, L., Kuo, P.C., \& Lim, J.W., Johnson, L.B., \& Farney, A.C., Weir, M.R., \& Bartlett, S.T. Mycophenolate mofetil reduces the risk of acute rejection less in African-American than in Caucasian kidney recipients. Transplantation, Vol. 65, No. 2, (January 1998), pp. 242-248, ISSN 1534-0608

Scott, L.J., McKeage, K., \& Keam, S.J., Plosker, G.L. Tacrolimus: a further update of its use in the management of organ transplantation. Drugs, Vol. 63, No. 12, (2003), pp. 124797, ISSN 0012-6667

Shaw, L.M., Figurski, M., \& Milone, M.C., Trofe, J., \& Bloom, R.D. Therapeutic drug monitoring of mycophenolic acid. Clinical Journal of the American Society of Nephrology, No. 2, Vol. 5, (September 2007), pp. 1062-1072, ISSN 1555-9041

Shaw, L.M., Holt, D.W., \& Keown, P., Venkataramanan, R., \& Yatscoff, R.W. Current opinions on therapeutic drug monitoring of immunosuppressive drugs. Clinical Therapeutics, Vol. 21, No. 10, (October 2002), pp. 1632-1652, ISSN 0149-2918

Shaw, L.M., Holt, D.W., \& Oellerich, M., Meiser, B., \& van Gelder, T., Shaw, L.M., \& Holt DW, Oellerich M. Current issues in therapeutic drug monitoring of mycophenolic 
acid: report of a roundtable discussion. Therapeutic Drug Monitoring, No. 23, Vol. 4, (August 2001), pp. 305-315, ISSN 0163-4356

Shaw, L.M., Korecka, M., \& Aradhye, S., Grossman, R., \& Bayer, L., Innes, C., \& Cucciara, A., Barker, C., \& Naji, A., Nicholls, A., \& Brayman, K. Mycophenolic acid area under the curve values in African American and Caucasian renal transplant patients are comparable. Journal of Clinical Pharmacology, Vol. 40, No. 6, (June 2000), pp. 624-633, ISSN 1552-4604

Shaw, L.M., Mick, R., \& Nowak, I., Korecka, M., \& Brayman, K.L. Pharmacokinetics of mycophenolic acid in renal transplant patients with delayed graft function. Journal of Clinical Pharmacology, Vol. 38, No. 3, (March 1998), pp. 268-275, ISSN 1552-4604

Sollinger,. H.W., Belzer, F.O., \& Deierhoi, M.H., Diethelm, A.G., \& Gonwa, T.A., Kauffman, R.S., \& Klintmalm, G.B., McDiarmid, S.V., \& Roberts, J., Rosenthal, J.T. RS-61443 (mycophenolate mofetil). A multicenter study for refractory kidney transplant rejection. Annals of Surgery, Vol. 216, No. 4, (October 1992), pp. 513-518, ISSN 15281140

Staatz, C., Taylor, P., \& Tett, S. Low tacrolimus concentrations and increased risk of early acute rejection in adult renal transplantation. Nephrology Dialysis Transplantation, Vol. 16, No. 9, (September 2001), pp. 1905-1909, ISSN 1460-6235

Staatz, C.E., \& Tett, S.E. Clinical pharmacokinetics and pharmacodynamics of tacrolimus in solid organ transplantation. Clinical Pharmacokinetics, Vol. 43, No. 10, (2004), pp. 623-53, ISSN 0312-5963

Staatz, C.E., \& Tett, S.E. Pharmacokinetic Considerations Relating to Tacrolimus Dosing in the Elderly. Drugs Aging, Vol. 22, No. 7, (2002), pp. 541-557, ISSN 1170-229X

Stein, C.M., Sadeque, A.J., \& Murray, J.J., Wandel, C., \& Kim, R.B., Wood, A.J. Cyclosporine pharmacokinetics and pharmacodynamics in African American and white subjects. Clinical Pharmacology and Therapeutics, Vol. 69, No. 5, (May 2001), pp. 317-323, ISSN 0009-9236

Takahashi, K., Ochiai, T., \& Uchida, K., Yasumura, T., \& Ishibashi, M., Suzuki, S., \& Otsubo, O., Isono, K., \& Takagi, H., Oka, T. Pilot study of mycophenolate mofetil (RS-61443) in the prevention of acute rejection following renal transplantation in Japanese patients. Transplantation Proceedings, No. 27, Vol. 1, (February 1995), pp. 1421-1424, ISSN 0041-1345

ter Meulen, C.G., van Riemsdijk, I., \& Hené, R.J., Christiaans, M.H., \& Borm, G.F., van Gelder, T., \& Hilbrands, L.B., Weimar, W., \& Hoitsma, A.J. Steroid-withdrawal at 3 days after renal transplantation with anti-IL-2 receptor alpha therapy: A prospective,randomized, multicenter study. American Journal of Transplantation, Vol. 4, No. 5, (May 2004), pp. 803-10, ISSN 1600-6143

Toda, F., Tanabe, K., \& Ito, S., Shinmura, H., Tokumoto, T., \& Ishida, H., Toma, H. Tacrolimus trough level adjustment after administration of fluconazole to kidney recipients. Transplantation Proceedings, Vol. 34, No. 5, (August 2002), pp. 1733-1735, ISSN 0041-1345

Tsuchiya, N., Satoh, S., \& Tada, H., Li, Z., \& Ohyama, C., Sato, K., \& Suzuki, T., Habuchi, T., \& Kato, T. Influence of CYP3A5 and MDR1 (ABCB1) polymorphisms on the pharmacokinetics of tacrolimus in renal transplant recipients. Transplantation, Vol. 78, No. 4, (October 2004), pp. 1182-1187, ISSN 1434-0608 
Tuteja, S., Alloway, R., \& Johnson, J., Gaber, O. The effect of gut metabolism on tacrolimus bioavailability in renal transplant recipients. Transplantation, Vol. 71, No. 9, (April 2001), pp. 1303-1307, ISSN 1534-0608

Undre, N.A., \& Schäfer, A. Factors affecting the pharmacokinetics of tacrolimus in the first year after renal transplantation. Transplantation Proceedings, Vol. 30, No. 4, (June 1998), pp. 1261-1263, ISSN 0041-1345

Undre, N.A. Pharmacokinetics of tacrolimus-based combination therapies. Nephrology Dialysis Transplantation, Vol. 18, No. S1, (May 2003), pp. i12-i15, ISSN 1460-6235

Undre, N.A., Stevenson, P., \& Schäfer, A. Pharmacokinetics of Tacrolimus: Clinically Relevant Aspects. Transplantation Proceedings, Vol. 31, No. S7A, (November 1999), pp. 21S-24S, ISSN 0041-1345

Undre, N.A., van Hooff, J., \& Christiaans, M., Vanrenterghem, Y., \& Donck, J., Heeman, U., \& Kohnle, M., Zanker, B., \& Land, W., Morales, J.M., \& Andrés, A., Schäfer, A., \& Stevenson, P. Pharmacokinetics of FK 506 and mycophenolic acid after the administration of a FK 506-based regimen in combination with mycophenolate mofetil in kidney transplantation. Transplantation Proceedings, Vol. 30, No. 4, (June 2002), pp. 1299-1302, ISSN 0041-1345

Utecht, K.N., Hiles, J.J., \& Kolesar, J. Effects of Genetic Polymorphisms on the Pharmacokinetics of Calcineurin Inhibitors. American Journal of Health-System Pharmacy, Vol. 63, No. 23, (December 2002), pp. 2340-2348, ISSN 1079-2082

van Duijnhoven, E.M., Boots, J.M., \& Christiaans, M.H., Stolk, L.M., \& Undre, N.A., van Hooff, J.P. Increase in tacrolimus trough levels after steroid withdrawal. Transplant International, Vol. 16, No. 10, (October 2003), pp. 721-725, ISSN 0934-0874

Van Gelder T. Drug interactions with tacrolimus. Drug Safety, Vol. 25, No. 10, (2002), pp. 707-12, ISSN 0114-5916

van Gelder, T., Hilbrands, L.B., \& Vanrenterghem, Y., Weimar, W., \& de Fijter, J.W., Squifflet, J.P., \& Hené, R.J., Verpooten, G.A., \& Navarro, M.T., Hale, M.D., Nicholls, A.J. A randomized double-blind, multicenter plasma concentration controlled study of the safety and efficacy of oral mycophenolate mofetil for the prevention of acute rejection after kidney transplantation. Transplantation, Vol. 68, No. 2, (July 1999), pp. 261-266, ISSN 1534-0608

Van Gelder, T., Le Meur, Y., \& Shaw, L.M., Oellerich, M., \& DeNofrio, D., Holt, C., \& Kaplan, B., Kuypers, D., \& Meiser, B., Toenshoff, B., \& Mamelok, R.D. Therapeutic drug monitoring of mycophenolate mofetil in transplantation. Therapeutic Drug Monitoring, Vol. 28 No. 2, (April 2006), pp. 145-154, ISSN 0163-4356

van-Duijnhoven, E.M, Christiaans, M., \& Undre, N., Stevenson, P., \&van Hooff, J. The effect of breakfast on the oral bioavailability of tacrolimus in diabetic and nondiabetic patients before transplantation. Transplantation Proceedings, Vol. 30, No. 4, (June 1998), pp. 1268-1270, ISSN 0041-1345

van-Duijnhoven, E.M., Christiaans, M.H., \& Boots, J.M., van Hooff, J.P. Evidence That Fasting Does Not Significantly Affect Trough Levels of Tacrolimus in Stable Renal Transplant Recipients. Transplantation Proceedings, Vol. 34, No. 5, (August 2002), pp. 1723-1725, ISSN 0041-1345

Vanrenterghem, Y., Lebranchu, Y., \& Hené, R., Oppenheimer, F., \& Ekberg, H. Double-blind comparison of two corticosteroid regimens plus mycophenolate mofetil and 
cyclosporine for prevention of acute renal allograft rejection. Transplantation, Vol. 70, No. 9, (November 2000), pp. 1352-1359, ISSN 1534-0608

Varis, T., Kivistö, K.T., \& Backman, J.T., Neuvonen, P.J. The cytochrome P450 3A4 inhibitor itraconazole markedly increases the plasma concentrations of dexamethasone and enhances its adrenal-suppressant effect. Clinical Pharmacology and Therapeutics, Vol. 68, No. 5, (November 2000), pp. 487-494, ISSN 0009-9236

Venkataramanan, R., Swaminathan, A., \& Prasad, T., Prasad, T., \& Jain, A., Zuckerman, S. Clinical pharmacokinetics of tacrolimus. Clinical Pharmacokinetics, Vol. 29, No. 6, (December 1995), pp. 404-430, ISSN 0312-5963

Vicari-Christensen, M., Repper, S., \& Basile, S., Young, D. Tacrolimus: review of pharmacokinetics, pharmacodynamics, and pharmacogenetics to facilitate practitioners understanding and offer strategies for educating patients and promoting adherence. Progress in Transplantation, Vol. 19, No. 3, (September 2009), pp. 277-842, ISSN 1526-9248

Wald, J.A., Law, R.M., \& Ludwig, E.A., Sloan, R.R., \& Middleton, E. Jr., Jusko, W.J. Evaluation of dose-related pharmacokinetics and pharmacodynamics of prednisolone in man. Journal of Pharmacokinetics and Biopharmaceutics, Vol. 20, No. 6, (December 1992), pp. 567-589, ISSN 0090-466X

Wallemacq, P.E., \& Verbeeck, R.K. Comparative Clinical Pharmacokinetics of Tacrolimus in Paediatric and Adult Patients. Clinical Pharmacokinetics, Vol. 40, No. 4, (2001), pp. 283-295, ISSN 0312-5963

Wang, C., Sun, J., \& Sheil, A.G., McCaughan, G.W., \& Bishop, G.A. A short course of methylprednisolone immunosuppression inhibits both rejection and spontaneous acceptance of rat liver allografts. Transplantation, Vol. 72, No. 1, (July 2001), pp. 4451, ISSN 1534-0608

Winkler, M., \& Christians, U. A risk-benefit assessment of tacrolimus in transplantation. Drug Safety, No. 12 Vol. 5, (May 1995), pp. 348-57, ISSN 0114-5916

World Health Organization (WHO). Global Activity in Organ Transplantation. Estimates 2008.

Yu, S., Wu, L., \& Jin, J., Yan, S., \& Jiang, G., Xie, H., \& Zheng, S. Influence of CYP3A5 gene polymorphisms of donor rather than recipient to tacrolimus individual dose requirement in liver transplantation. Transplantation, Vol. 81, No. 1, (January 2006), pp. 46-51, ISSN 1534-0608

Zucker, K., Rosen, A., \& Tsaroucha, A., de Faria, L., \& Roth, D., Ciancio, G., \& Esquenazi, V., Burke, G., \& Tzakis, A., Miller, J. Augmentation of mycophenolate mofetil pharmacokinetics in renal transplant patients receiving Prograf and CellCept in combination therapy. Transplantation Proceedings, Vol. 29, No. 1, (February-March 2002), pp.334-336, ISSN 0041-1345 


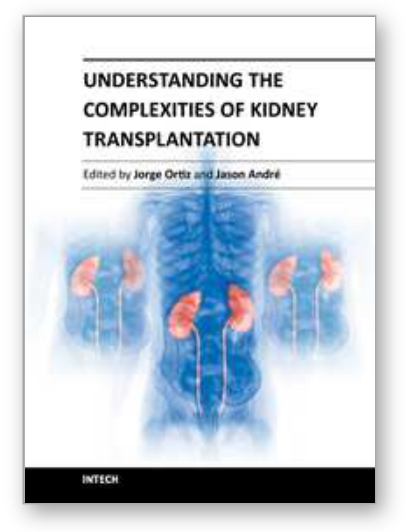

\author{
Understanding the Complexities of Kidney Transplantation \\ Edited by Prof. Jorge Ortiz
}

ISBN 978-953-307-819-9

Hard cover, 564 pages

Publisher InTech

Published online 06, September, 2011

Published in print edition September, 2011

Kidney transplantation is a complex field that incorporates several different specialties to manage the transplant patient. This book was created because of the importance of kidney transplantation. This volume focuses on the complexities of the transplant patient. In particular, there is a focus on the comorbidities and special considerations for a transplant patient and how they affect kidney transplant outcomes. Contributors to this book are from all over the world and are experts in their individual fields. They were all individually approached to add a chapter to this book and with their efforts this book was formed. Understanding the Complexities of Kidney Transplantation gives the reader an excellent foundation to build upon to truly understand kidney transplantation.

\title{
How to reference
}

In order to correctly reference this scholarly work, feel free to copy and paste the following:

Robles Piedras Ana Luisa and Monroy Funes Manuel Alejandro (2011). Clinical Pharmacokinetics of Triple Immunosuppression Scheme in Kidney Transplant (Tacrolimus, Mycophenolate Mofetil and Corticosteroids), Understanding the Complexities of Kidney Transplantation, Prof. Jorge Ortiz (Ed.), ISBN: 978-953-307-819-9, InTech, Available from: http://www.intechopen.com/books/understanding-the-complexities-of-kidneytransplantation/clinical-pharmacokinetics-of-triple-immunosuppression-scheme-in-kidney-transplanttacrolimus-mycophe

\section{INTECH}

open science | open minds

\author{
InTech Europe \\ University Campus STeP Ri \\ Slavka Krautzeka 83/A \\ 51000 Rijeka, Croatia \\ Phone: +385 (51) 770447 \\ Fax: +385 (51) 686166 \\ www.intechopen.com
}

\author{
InTech China \\ Unit 405, Office Block, Hotel Equatorial Shanghai \\ No.65, Yan An Road (West), Shanghai, 200040, China \\ 中国上海市延安西路65号上海国际贵都大饭店办公楼 405 单元 \\ Phone: +86-21-62489820 \\ Fax: $+86-21-62489821$
}


(C) 2011 The Author(s). Licensee IntechOpen. This chapter is distributed under the terms of the Creative Commons Attribution-NonCommercialShareAlike-3.0 License, which permits use, distribution and reproduction for non-commercial purposes, provided the original is properly cited and derivative works building on this content are distributed under the same license. 